University of Nebraska - Lincoln

DigitalCommons@University of Nebraska - Lincoln

Mechanical \& Materials Engineering Faculty

Publications

Mechanical \& Materials Engineering,

Department of

2000

\title{
The State and Future of Mars Polar Science and Exploration
}

Stephen M. Clifford

Lunar and Planetary Institute, Houston, TX

David Crisp

Jet Propulsion Laboratory, Pasadena, CA

David A. Fisher

Geological Survey of Canada, Ottawa

Ken E. Herkenhoff

U.S. Geological Survey, Flagstaff, AZ

Suzanne E. Smrekar

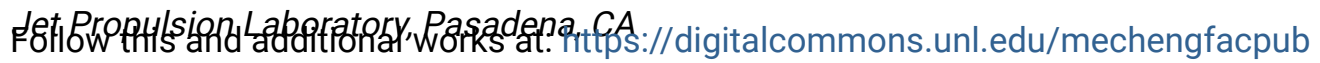

Part of the Mechanical Engineering Commons

See next page for additional authors

Clifford, Stephen M.; Crisp, David; Fisher, David A.; Herkenhoff, Ken E.; Smrekar, Suzanne E.; Thomas, Peter C.; Wynn-Williams, David D.; Zurek, Richard W.; Barnes, Jeffrey R.; Bills, Bruce G.; Blake, Erik W.; Calvin, Wendy M.; Cameron, Jonathan M.; Carr, Michael H.; Christensen, Philip R.; Clark, Benton C.; Clow, Gary D.; Cutts, James A.; Dahl-Jensen, Dorthe; Durham, William B.; Fanale, Fraser P.; Farmer, Jack D.; Forget, Francois; Gotto-Azuma, Kumiko; Grard, Rejean; Haberle, Robert M.; Harrison, William; Harvey, Ralph; Howard, Alan D.; Ingersoll, Andy P.; James, Philip B.; Kargel, Jeffrey S.; Kieffer, Hugh H.; Larsen, Janus; Lepper, Kenneth; Malin, Michael C.; McCleese, Daniel J.; Murray, Bruce; Nye, John F.; Paige, David A.; Platte, Stephen R.; Plaut, Jef f J.; Reeh, Niels; Rice, James W.; Smith, David E.; Stoker, Carol R.; Tanaka, Kenneth L.; Mosley-Thompson, Ellen; Thorsteinsson, Thorsteinn; Wood, Stephen E.; Zent, Aaron; Zuber, Maria T.; and Zwally, H. Jay, "The State and Future of Mars Polar Science and Exploration" (2000).

Mechanical \& Materials Engineering Faculty Publications. 17.

https://digitalcommons.unl.edu/mechengfacpub/17

This Article is brought to you for free and open access by the Mechanical \& Materials Engineering, Department of at DigitalCommons@University of Nebraska - Lincoln. It has been accepted for inclusion in Mechanical \& Materials Engineering Faculty Publications by an authorized administrator of DigitalCommons@University of Nebraska Lincoln. 


\section{Authors}

Stephen M. Clifford, David Crisp, David A. Fisher, Ken E. Herkenhoff, Suzanne E. Smrekar, Peter C. Thomas, David D. Wynn-Williams, Richard W. Zurek, Jeffrey R. Barnes, Bruce G. Bills, Erik W. Blake, Wendy M. Calvin, Jonathan M. Cameron, Michael H. Carr, Philip R. Christensen, Benton C. Clark, Gary D. Clow, James A. Cutts, Dorthe Dahl-Jensen, William B. Durham, Fraser P. Fanale, Jack D. Farmer, Francois Forget, Kumiko Gotto-Azuma, Rejean Grard, Robert M. Haberle, William Harrison, Ralph Harvey, Alan D. Howard, Andy P. Ingersoll, Philip B. James, Jeffrey S. Kargel, Hugh H. Kieffer, Janus Larsen, Kenneth Lepper, Michael C. Malin, Daniel J. McCleese, Bruce Murray, John F. Nye, David A. Paige, Stephen R. Platte, Jef $f$ J. Plaut, Niels Reeh, James W. Rice, David E. Smith, Carol R. Stoker, Kenneth L. Tanaka, Ellen Mosley-Thompson, Thorsteinn Thorsteinsson, Stephen E. Wood, Aaron Zent, Maria T. Zuber, and H. Jay Zwally 


\title{
The State and Future of Mars Polar Science and Exploration
}

\author{
Stephen M. Clifford, ${ }^{1}$ David Crisp, ${ }^{2}$ David A. Fisher, ${ }^{3}$ Ken E. Herkenhoff, ${ }^{4}$ Suzanne E. Smrekar, ${ }^{2}$ Peter C. Thomas, ${ }^{5}$ David \\ D. Wynn-Williams, ${ }^{6}$ Richard W. Zurek, ${ }^{2}$ Jeffrey R. Barnes, ${ }^{7}$ Bruce G. Bills, ${ }^{8}$ Erik W. Blake, ${ }^{9}$ Wendy M. Calvin, ${ }^{4}$ Jonathan \\ M. Cameron, ${ }^{2}$ Michael H. Carr, ${ }^{10}$ Philip R. Christensen, ${ }^{11}$ Benton C. Clark, ${ }^{12}$ Gary D. Clow, ${ }^{13}$ James A. Cutts, ${ }^{2}$ Dorthe \\ Dahl-Jensen, ${ }^{14}$ William B. Durham, ${ }^{15}$ Fraser P. Fanale, ${ }^{16}$ Jack D. Farmer, ${ }^{11}$ Francois Forget, ${ }^{17}$ Kumiko Gotto- \\ Azuma, ${ }^{18}$ Rejean Grard,${ }^{19}$ Robert M. Haberle, ${ }^{20}$ William Harrison, ${ }^{21}$ Ralph Harvey, ${ }^{22}$ Alan D. Howard, ${ }^{23}$ \\ Andy P. Ingersoll, ${ }^{24}$ Philip B. James, ${ }^{25}$ Jeffrey S. Kargel ${ }^{4}$ Hugh H. Kieffer, ${ }^{4}$ Janus Larsen, ${ }^{14}$ Kenneth \\ Lepper, ${ }^{26}$ Michael C. Malin, ${ }^{27}$ Daniel J. McCleese, ${ }^{2}$ Bruce Murray, ${ }^{24}$ John F. Nye, ${ }^{28}$ David A. Paige, ${ }^{29}$ \\ Stephen R. Platt, ${ }^{30}$ Jeff J. Plaut, ${ }^{2}$ Niels Reeh, ${ }^{31}$ James W. Rice, ${ }^{32}$ Jr., ${ }^{21}$ David E. Smith, ${ }^{8}$ Carol \\ R. Stoker ${ }^{20}$ Kenneth L. Tanaka ${ }^{4}$ Ellen Mosley-Thompson, ${ }^{33}$ Thorsteinn Thorsteinsson, ${ }^{34}$ \\ Stephen E. Wood, ${ }^{35}$ Aaron Zent, ${ }^{20}$ Maria T. Zuber ${ }^{36}$ and H. Jay Zwally ${ }^{8}$ \\ ${ }^{1}$ Lunar and Planetary Institute, 3600 Bay Area Boulevard, Houston, Texas 77058; ${ }^{2}$ Jet Propulsion Laboratory, Pasadena, California $91109 ;{ }^{3}$ Terrain Science \\ Division, Geological Survey of Canada, Ottawa, Ontario KIA OE8, Canada; ${ }^{4}$ U.S. Geological Survey, Flagstaff, Arizona 8600I; ${ }^{5}$ Department of Astronomy, \\ Cornell University, Ithaca, New York 14853; ${ }^{6}$ British Antarctic Survey, Natural Environmental Research Council, Cambridge CB3 OET, United Kingdom; \\ ${ }^{7}$ College of Oceanic and Atmospheric Sciences, Oregon State University, Oregon 97331; ${ }^{8}$ Geodynamics Branch, NASA Goddard Space Flight Center, Greenbelt, \\ Maryland 20771; ${ }^{9}$ Icefield Instruments Inc., Whitehorse, Yukon Canada, Y1A 5H4, Canada; ${ }^{10}$ U.S. Geological Survey, Menlo Park, California $94025 ;$ \\ ${ }^{11}$ Department of Geology, Arizona State University, Tempe, Arizona 85287; ${ }^{12}$ Lockheed Martin Astronautics, Denver, Colorado 8020; ${ }^{13}$ U.S. Geological \\ Survey, Denver Federal Center, Denver, Colorado 80225; ${ }^{14}$ Geofysisk Afdeling, Niels Bohr Institut for Astronomi, Fysik og Geofysik, DK-2100 København \\ OE, Denmark; ${ }^{15}$ Lawrence Livermore National Laboratory, University of California-Berkeley, Livermore, California $94550 ;{ }^{16}$ Hawaii Institute of \\ Geophysics and Planetology, Honolulu, Hawaii 96822; ${ }^{17}$ Laboratoire de Météorologie Dynamique du C.N.R.S., Université de Paris 6, F-75252 Paris \\ Cedex 05, France; ${ }^{18}$ Nagaoka Institute of Snow and Ice Studies NIED, 187-16 Suyoshi Nagaoka Niigata, Japan; ${ }^{19}$ European Space Agency/ESTEC, \\ NL-2200 AG Noordwijk, The Netherlands; ${ }^{20}$ Space Sciences Division, NASA Ames Research Center, Moffett Field, California 94035; ${ }^{21}$ Geophysical \\ Institute, University of Alaska-Fairbanks, 903 Koyukuk Drive, Fairbanks, Alaska 99775; ${ }^{22}$ Department of Geological Sciences, Case Western \\ Reserve University, Cleveland, Ohio 44106; ${ }^{23}$ Department of Environmental Science, University of Virginia, Charlottesville, Virginia 22903; \\ ${ }^{24}$ Division of Geological and Planetary Sciences, California Institute of Technology, Pasadena, California 91125; ${ }^{25}$ Department of Physics \\ and Astronomy, University of Toledo, Toledo, Ohio 43606; ${ }^{26}$ Environmental Sciences Program, Department of Physics, Oklahoma State \\ University, Stillwater, Oklahoma 74078; ${ }^{27}$ Malin Space Science Systems, Inc., San Diego, California 92191; ${ }^{28}$ Department of Physics, \\ H. H. Wills Physics Laboratory, University of Bristol, Bristol BS8 1TL, United Kingdom; ${ }^{29}$ Department of Earth and Space Sciences, \\ University of California at Los Angles, Los Angles, California 90095; ${ }^{30}$ Snow and Ice Research Group, University of Nebraska- \\ Lincoln, Lincoln, Nebraska 68583; ${ }^{31}$ Danish Center for Remote Sensing, Technical University of Denmark, DK-2800 Lyngby, \\ Denmark; ${ }^{32}$ Lunar and Planetary Laboratory, University of Arizona, Tucson, Arizona 85721; ${ }^{33}$ Byrd Polar Research Center, \\ Ohio State University, Columbus, Ohio 43210; ${ }^{34}$ Alfred Wegener Institut fur Polar- und Meeresforschung, Columbusstrasse, \\ D-27568 Bremerhaven, Germany; ${ }^{35}$ Department of Atmospheric Sciences, University of Washington, Seattle, \\ Washington 98195; ${ }^{36}$ Department of Earth, Atmospheric and Planetary Sciences, Massachusetts \\ Institute of Technology, Cambridge, Massachusetts 02139 \\ E-mail: clifford@1pl.jsc.nasa.gov
}

Received July 20, 1999; revised October 25, 1999

As the planet's principal cold traps, the martian polar regions have accumulated extensive mantles of ice and dust that cover individual areas of $\sim 10^{6} \mathrm{~km}^{2}$ and total as much as $3-4 \mathrm{~km}$ thick. From the scarcity of superposed craters on their surface, these layered deposits are thought to be comparatively young-preserving a record of the seasonal and climatic cycling of atmospheric $\mathrm{CO}_{2}, \mathrm{H}_{2} \mathrm{O}$, and dust over the past $\sim 10^{5}-10^{8}$ years. For this reason, the martian polar deposits may serve as a Rosetta Stone for understanding the geologic and climatic history of the planet-documenting variations in insolation (due to quasiperiodic oscillations in the planet's obliquity and orbital elements), volatile mass balance, atmospheric composition, dust storm activity, volcanic eruptions, large impacts, catastrophic floods, solar luminosity, supernovae, and perhaps even a record of microbial life. Beyond their scientific value, the polar regions may soon prove important for another reason-providing a valuable and accessible reservoir of water to support the long-term human exploration of Mars. In this paper we assess the current state of Mars polar research, identify the key questions that motivate the exploration of the polar regions, discuss the extent to which current missions will address these questions, and speculate about what additional capabilities and investigations may be required to address the issues that remain outstanding.

Key Words: Mars, surface; Mars, atmosphere; Mars, climate; ices; exobiology. 


\section{INTRODUCTION}

Thirty-five years of investigations by robotic spacecraft have provided substantial evidence that the atmosphere and surface of Mars have undergone a lengthy and complex evolution. This conclusion is supported by the geologic diversity of the planet's surface, which has been extensively modified by impact, volcanic, tectonic, and eolian processes. But perhaps the greatest surprise has been the role of water.

Although a combination of low atmospheric pressure and subfreezing temperatures preclude the existence of liquid water on the surface of Mars today, the presence of valley networks and the degraded state of the planet's oldest terrains suggests that the climate may have been considerably different in the past (Masursky et al. 1977, Pollack et al. 1987, Carr 1999). Evidence of more recent fluvial activity is found along the periphery of the planet's northern plains, where huge scoured channels, tens of kilometers wide and hundreds of kilometers long, are incised up to a kilometer deep into the martian surface (Baker et al. 1992). The abrupt emergence of these channels from regions of collapsed and disrupted terrain and the enormous dimensions of the braided and streamlined forms found within their beds testify to an origin by catastrophic floods, apparently fed by the artesian discharge of subpermafrost groundwater (Carr 1979, Baker 1982, Scott et al. 1991). The recent identification of putative shorelines in the northern plains suggests that the water from these events may have contributed to one or more ice-covered lakes or seas that may have collectively covered as much as a third of the planet (Lucchitta et al. 1986; Parker et al. 1989, 1993; Scott et al. 1991, 1995; Head et al. 1998; Chapman 1994; Costard and Kargel 1995). These, and other lines of evidence, suggest that Mars is water-rich and may store the equivalent of a global ocean of water $\sim 0.5-1 \mathrm{~km}$ deep as ground ice and groundwater within its crust (Carr 1987).

Over time, the thermodynamic instability of water and ice at low latitudes has led to the progressive redistribution of $\mathrm{H}_{2} \mathrm{O}$ from surface and near-surface reservoirs to the planet's dominant cold traps at the poles (Farmer and Doms 1979, Clifford and Hillel 1983, Fanale et al. 1986, Zent et al. 1986, Mellon and Jakosky 1993). Contributing to the growth of these polar mantles of ice has been a significant component of entrained dust, scavenged from across the planet by frequent local and global dust storms (Murray et al. 1972, Soderblom et al. 1973, Cutts 1973). The precipitation of dust and $\mathrm{H}_{2} \mathrm{O}$ at the poles is thought to be aided by the condensation of atmospheric $\mathrm{CO}_{2}$ during the formation of the seasonal polar caps in the hemispheric fall and winter (Pollack et al. 1979). In this same way, ash from volcanic eruptions, fallout from large impacts, evaporites from subliming lakes and seas, and perhaps even samples of microbial life may have been brought to the poles and precipitated from the atmosphere, to be embedded and preserved within the growing mantles of frozen sediment. The observation of extensive layering within these deposits, combined with estimates of their age inferred from the number of superposed craters, suggests that they may preserve a stratigraphic record of climate change that ranges from months to millions of years, modulated by quasiperiodic changes in the planet's orbit and obliquity (Murray et al. 1972, Cutts 1973, Toon et al. 1980, Howard et al. 1982, Cutts et al. 1981, Cutts and Lewis 1982, Herkenhoff and Plaut 2000).

As identified by the participants in the First International Conference on Mars Polar Science and Exploration (Clifford et al. 2000), the principal goal of Mars polar science and exploration is to determine whether this complex evolution has left an interpretable record of climatic and geologic history preserved within the stratigraphy of the polar sediments. If so, then unraveling its expression from the intertwined variations in mass balance that have created the deposits will require a variety of atmospheric, surface, and subsurface observations, innovative exploration tools, and the development of a reliable in situ method of dating the polar ice. Most importantly, in order to understand the origin of past changes we need to understand the planet's current climate, with specific regard to the circulation of the atmosphere and seasonal cycles of $\mathrm{CO}_{2}, \mathrm{H}_{2} \mathrm{O}$, and dust.

Scientific investigations of the polar regions can be divided into four general areas of research: geology, climate, glaciology and hydrology, and the search for life. Among the questions these efforts seek to address are: What is the composition, structure, and chronology expressed in the stratigraphy of the polar deposits? What is their mass and energy budget, and what processes control them on seasonal and longer timescales? What is their dynamical history? And, finally, are there places within the polar regions where liquid water is or was present that may have provided habitats for past or present life?

Early efforts to address these questions led to considerable advances in our knowledge of the martian polar terrains and helped identify many key questions to be addressed by current and future investigations (e.g., as summarized by Thomas $e$ a al. (1992) and Kieffer and Zent (1992)). Ongoing observations by the Mars Global Surveyor (MGS) spacecraft have resulted in a number of new and exciting findings. Over the next several years, the additional data anticipated from the Mars Polar Lander, Deep Space-2 microprobes, Mars Surveyor 2001 Orbiter, and Mars Express spacecraft will contribute to a further advancement in our understanding of the physical properties and seasonal evolution of the polar layered deposits. In this paper we assess the current state of Mars polar science and exploration and discuss some of the fundamental questions that remain to be addressed.

\section{THE MARTIAN POLAR REGIONS}

\subsection{Composition and Geology}

Long before the first spacecraft were sent to Mars, telescopic observations had revealed that the planet possesses polar caps that undergo large seasonal variations in size. Thermal modeling by Leighton and Murray (1966) demonstrated that the changes in polar insolation due to the planet's $25^{\circ}$ obliquity were sufficient to cause winter temperatures cold enough for $\mathrm{CO}_{2}$ to precipitate 
(a)

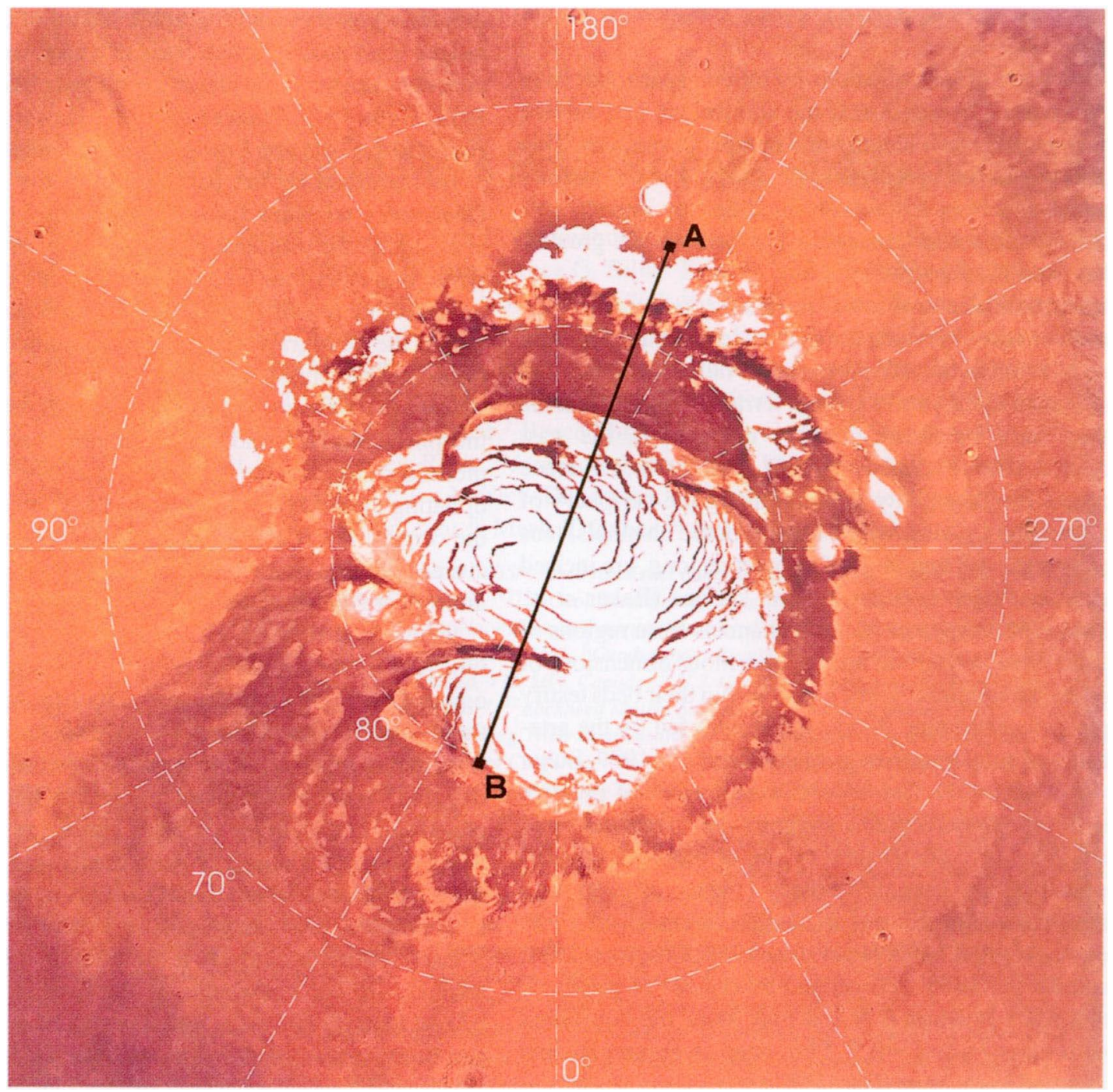

(b)

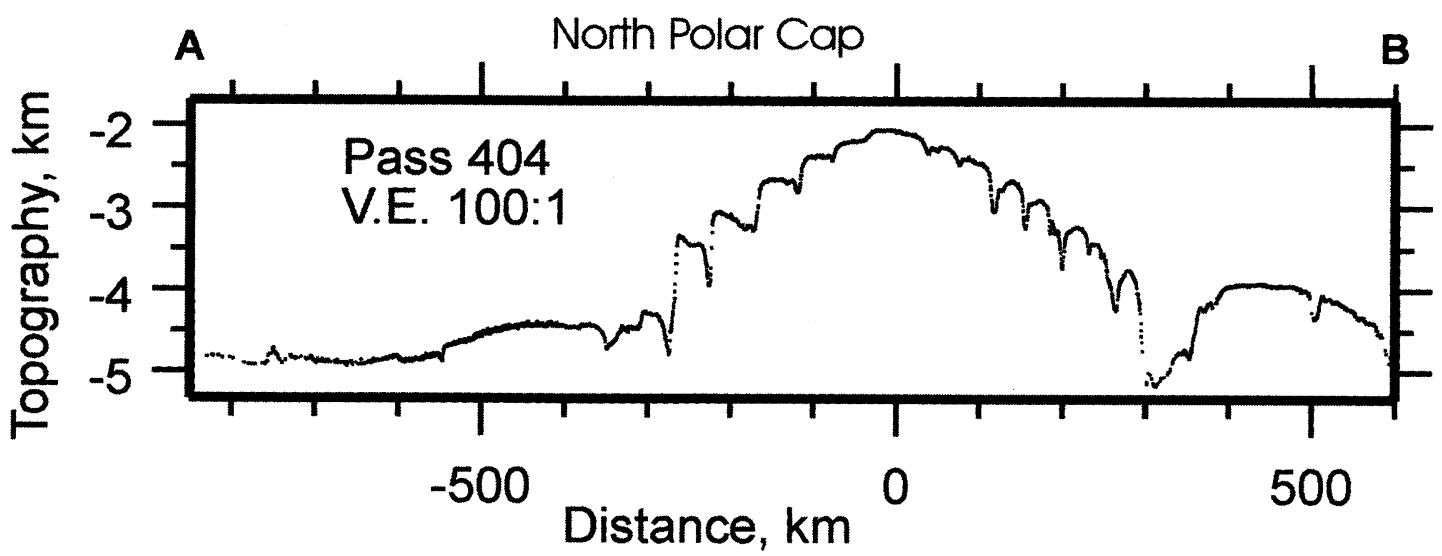

FIG. 1. (a) Color mosaic digital image map (polar projection) of the north polar deposits (Vistitas Borealis) showing the ground track of the MOLA topographic profile in (b) (USGS CD-ROM VO_2001). The most notable features of the deposits are the white perennial ice cap (which overlies several kilometers of layered terrain), the dark troughs that spiral outward from the pole, several large erosional reentrants along the periphery of the deposits (the largest of which, Chasma Boreale, nearly bisects the perennial ice cap), and the polar erg-a dark band of dunes that encircle the cap. (b) MOLA topographic profile of the north polar cap obtained on MGS Pass 404 (Zuber et al. 1998). The ground track of the profile crosses directly over the north pole and provides a measure of the height of the northern ice cap above the surrounding plains. The $M G S$ spacecraft was pointing about $50^{\circ}$ off-nadir for this profile (provided by MOLA Science Team). 


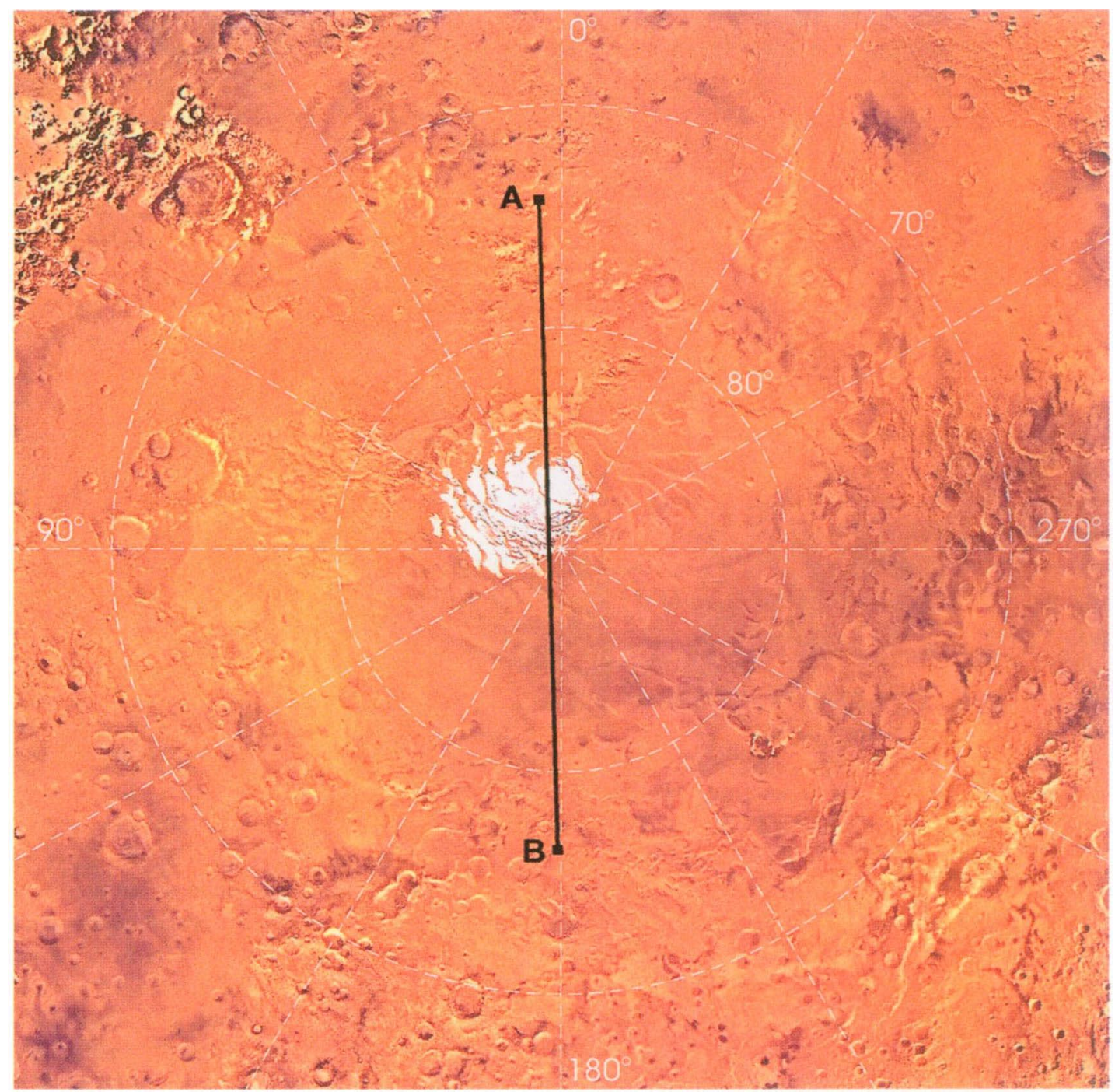

(d)

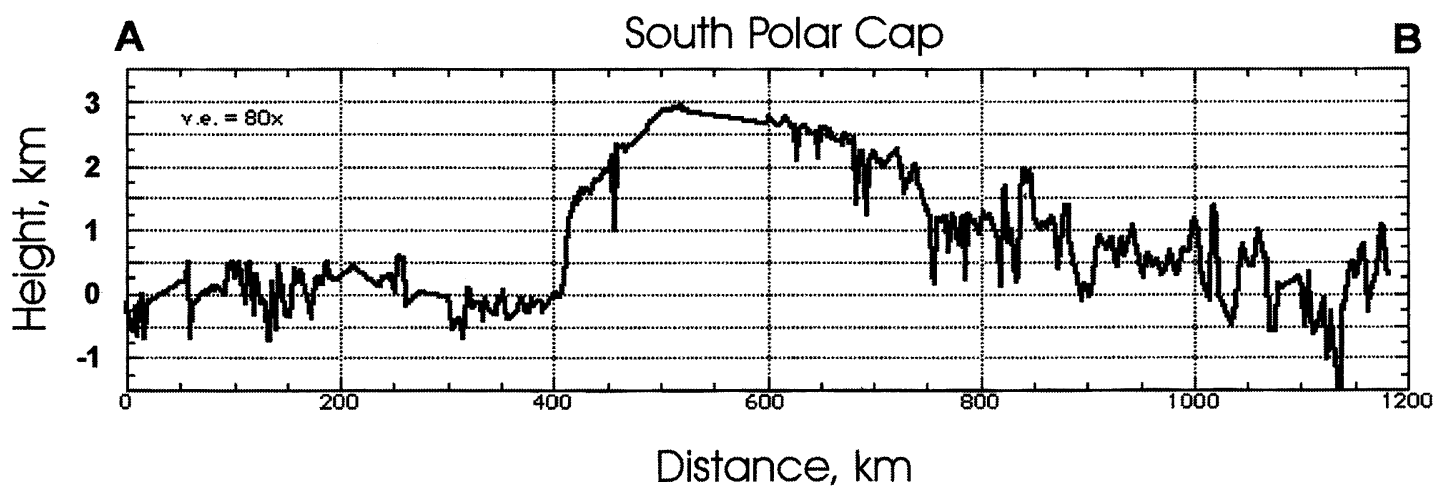

FIG. 1-Continued (c) Color mosaic digital image map (polar projection) of the south polar deposits (Planum Australe) showing the ground track of the Viking stereo-image derived topographic profile in (d) (USGS CD-ROM VO_2006). While the south perennial ice cap is significantly smaller than the one found in the north ( $\sim 400 \mathrm{~km}$ vs $1100 \mathrm{~km}$ diameter), the underlying (and mostly defrosted) layered terrain occupies an area nearly twice as large as its northern counterpart. Although not clearly visible in this mosaic, the south polar deposits share several geomorphic similarities with those in the north-the most notable exception being the dominance of equatorward-facing scarps over troughs within the deposits' interior. (d) Viking stereo image-derived topographic profile that crosses almost directly over the south pole (Schenk and Moore 2000). A rheologic study of the south polar cap, based on this profile, indicates that the $\sim 3-\mathrm{km}$ height of the perennial ice above the surrounding plain is inconsistent with a predominantly $\mathrm{CO}_{2}$ composition, implying that the dominant volatile component of the southern cap is water ice (Nye et al. 2000). Subsequent higher resolution profiles obtained by MOLA (Smith et al. 1999) have revealed a similar strucutre. 
from the atmosphere. As a result, as much as one-quarter of the atmosphere condenses out at the winter pole, producing a seasonal deposit $\sim 1 \mathrm{~m}$ thick that covers the latitudes poleward of $\sim 50^{\circ}$. By late spring, the increase in insolation causes the seasonal cap to sublime away, revealing a considerably smaller residual cap that survives the hemispheric summer (James et al. 2000).

While thermal and spectroscopic observations made by Mariner 7 confirmed that the composition of the seasonal caps was $\mathrm{CO}_{2}$ (Neugebauer et al. 1971), the composition of the smaller perennial caps (Fig. 1) remained uncertain until the arrival of the Viking mission in 1976. The Viking Orbiter Infrared Thermal Mapper (IRTM) measured summertime brightness temperatures as high as $205 \mathrm{~K}$ over the north perennial cap, well in excess of the $148 \mathrm{~K}$ sublimation temperature of $\mathrm{CO}_{2}$ (Kieffer et al. 1976). Concurrent atmospheric water vapor measurements confirmed that the polar atmosphere was saturated with respect to a surface reservoir of $\mathrm{H}_{2} \mathrm{O}$ (Farmer et al. 1976). These observations demonstrated conclusively that the composition of the volatile component of the perennial cap was water ice.

However, the high polar temperatures recorded by Viking could not be explained by the presence of ice alone. Indeed, IRTM measurements indicated a polar albedo of $0.45-$ well below the value of 0.7 that characterizes clean terrestrial snow. This low albedo has been attributed to the deposition and entrainment of atmospheric dust, based on both the "reddish" spectral characteristics of the polar ice (Kieffer 1979, Thomas and Weitz 1989) and high-resolution images of the scarps visible within the perennial cap. These images have revealed the presence of numerous horizontal layers whose stratigraphic variations in thickness and albedo are thought to reflect climatic variations in the quantity and relative abundance of dust and water ice deposited on the cap (Murray et al. 1972, Cutts 1973, Howard et al. 1982, Thomas et al. 1992), However, the density, and therefore the bulk composition of the polar deposits, has proven difficult to constrain (Malin 1986, Zuber et al. 1998).

With the identification of $\mathrm{H}_{2} \mathrm{O}$ in the north, it was expected that the composition of the south perennial cap would also prove to be water ice. Yet, throughout the following southern summer, Viking IRTM observations failed to reveal south polar surface temperatures in excess of $148 \mathrm{~K}$ (Kieffer 1979). Atmospheric water vapor levels were also substantially lower than those previously recorded in the north (Jakosky and Farmer 1982). These observations indicate that the south perennial cap remained covered with $\mathrm{CO}_{2}$ throughout the martian year. Whatever the reason for the year-round survival of $\mathrm{CO}_{2}$, the low temperatures recorded over the southern cap mean that it should act as a cold trap for atmospheric $\mathrm{H}_{2} \mathrm{O}$ and therefore be at least partially composed of water ice (Jakosky and Farmer 1982).

The polar terrains are among the youngest surfaces to be found on Mars. In the north, their extreme youth is supported by Viking high-resolution images that fail to reveal any craters with diameters $>300 \mathrm{~m}$ within the $\sim 10^{6} \mathrm{~km}^{2}$ covered by the deposits (Cutts et al. 1976, Herkenhoff et al. 1997). This observation ar- gues for an age of the exposed surface that is less than about $10^{5}$ years - a result that may reflect either the deposition of new material or the continuous reworking of older material at the pole (Toon et al. 1980, Herkenhoff and Plaut 2000). In the south, the identification of $\sim 15$ craters with diameters $>800 \mathrm{~m}$ (Plaut et al. 1988 ) indicates a surface age of 7-15 million years, depending on the recent martian cratering flux (Herkenhoff and Plaut 2000). These results imply a difference in surface age between the north and south polar layered terrains of 2 orders of magnitude. In particular, the surface age of the south polar layered terrain is greater (on average) than the timescales of martian orbit/axial variations that are thought to produce global climate variations ( 10 $-10^{6}$ years; Ward 1979, 1992; Lasker and Robutel 1993; Touma and Wisdom 1993). The recent resurfacing (deposition or erosion) rates for the polar layered deposits that are implied by the observed crater densities are 60-120 m/Ma in the south and at least $1165 \mathrm{~m} / \mathrm{Ma}$ in the north (Herkenhoff and Plaut 2000). These results are at odds with the concept that the processes that form the layers are hemispherically symmetric to first order, and suggest that the $\sim 6-\mathrm{km}$ elevation difference between the polar regions has had a major difference on polar deposition.

The two geologic units common to both poles are: (i) the residual polar ice cap and (ii) the polar layered deposits (Murray et al. 1972, Soderblom et al. 1973, Tanaka and Scott 1987). The polar ice caps are simply the high-albedo surficial ice units that survive the summer at both poles and appear to lie directly upon the layered deposits. The two units are distinguished by their temperatures and albedos, but the residual caps may simply be the most recent layer in the process of forming. Inasmuch as the layers almost certainly represent geographic and temporal variations in the mass balance of ice and dust, the present-day residual caps are most likely comparable to only specific parts of the layered deposits. Given the uncertainty in how the present mass balance varies over the caps (Kieffer and Zent 1992), the residual ice caps could correlate with particular "halves" of layer pairs, conformable transitions between layers, or with unconformities between sets of layers. The polar layered deposits are characterized by numerous, laterally extensive, horizontal layers that have apparent individual thicknesses ranging from $\sim 300 \mathrm{~m}$ down to the resolution limits of the available imagery (currently $\sim 1.5$ m/pixel, e.g., Fig. 2) (Blasius et al. 1982, Herkenhoff and Murray 1990, Thomas et al. 1992, M. C. Malin, remarks presented at the First International Conference on Mars Polar Science and Exploration, 1998). In the north, the layered deposits overlie the moderately cratered $(\sim 2-3 \mathrm{Ga})$ plains, while in the south, they blanket the ancient ( $\sim 4 \mathrm{Ga}$ ) heavily cratered highlands.

As discussed previously, the layered deposits appear to be composed of a mixture of water ice and dust in stratigraphically variable proportions. However, variations in surface relief appear to contribute to the observed layering as well. Terracing is visible in both Mariner 9 and Viking Orbiter images (Murray et al. 1972, Blasius et al. 1982, Herkenhoff and Murray 1990), as well as in topographic profiles of layered exposures 
a

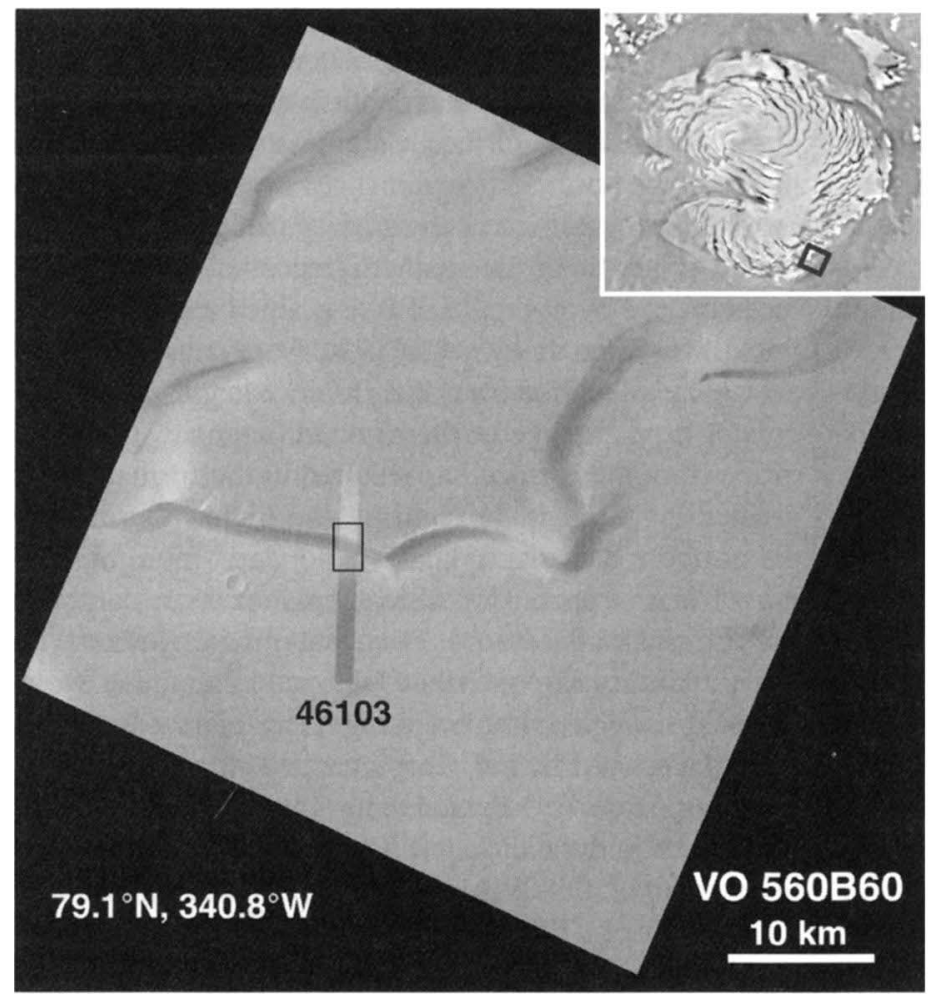

b

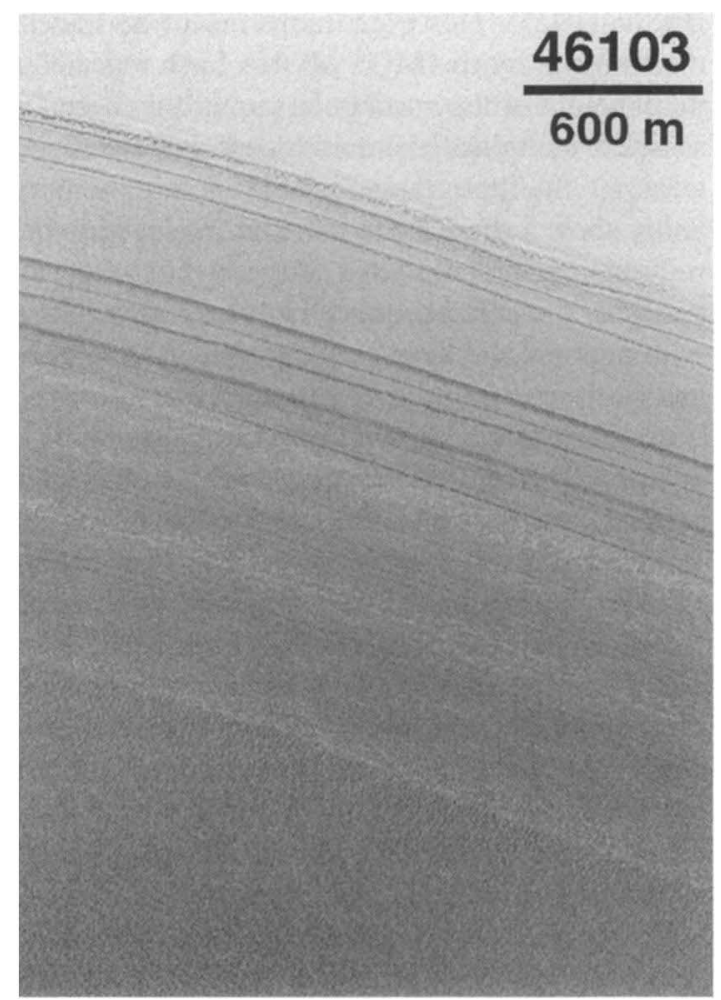

FIG. 2. Layered stratigraphy of the north polar deposits. (a) Photomosaic inset of north polar cap at upper right corner shows the relative location of the larger Viking Orbiter image (560B60) of the polar deposit's equatorward-facing outer (terminal) scarp. The Viking image provides the geologic context and indicates the location of (b), a Mars Orbiter Camera image (SPO-2-461/03) which shows that the fine-scale layering in the polar scarp extends down to limit of resolution (NASA/JPL/MSSS).

obtained by the Mars Orbiter Laser Altimeter (MOLA) (Zuber et al. 1998). In addition, recent high-resolution images obtained by the Mars Orbiter Camera (MOC) reveal that, where the layers are exposed along scarps, they often form ridges (M. C. Malin, remarks presented at the First International Conference on Mars Polar Science and Exploration, 1998). Similar layering is also observed in ice sheets on Earth, where it originates from stratigraphic variations in ice crystal size (Paterson 1981).

In the north, the residual polar ice cap and layered deposits are zoextensive and occupy much of the region poleward of $80^{\circ} \mathrm{N}$. Together, they compose the remnant ice cap, which has a diamzter of roughly $1100 \mathrm{~km}$. Surrounding the cap is a dark band of Junes called the polar erg. The dunes are typically $10-50 \mathrm{~m}$ high and spaced $1-2 \mathrm{~km}$ apart. The thermal inertia of the dune material uppears to be too low for sand, suggesting that it may be comoosed of smaller particles that have been aggregated by electrostatic forces, or some other cementing agent, into larger assemJlages capable of transport by the circumpolar winds (Herken1off and Vasavada 1999). Because the thermophysical properties of the polar dunes are so different from those of dunes at low atitudes, they appear to have been formed by a process unique to he pole. This conclusion is supported by the geologic relationships observed between the dunes and erosional scarps found within the polar layered deposits, evidence which indicates that at least some of the material in the polar erg was derived from these deposits (Thomas 1982, Thomas and Weitz 1989).

As seen in Fig. 1a, the most distinctive characteristic of the northern cap is the dark pattern of curvilinear troughs that swirl outward in a counterclockwise direction from the pole. Individual troughs are typically several hundred kilometers long, 5-15 km wide, and reach depths of 0.1-1 km; while the surface slopes, exhibited by their bordering scarps, may range from $1^{\circ}-$ $15^{\circ}$ (Blasius et al. 1982, Zuber et al. 1998). Within a single trough, individual layers can often be traced for hundreds of kilometers-a finding that suggests the layers are continuous over a large expanse of the cap.

Also visible in Fig. 1a are several major erosional reentrants. The largest of these, Chasma Boreale $\left(85^{\circ} \mathrm{N}, 0^{\circ} \mathrm{W}\right)$, nearly bisects the cap-extending from deep within the cap's interior to its outer edge over a distance of $\sim 500 \mathrm{~km}$. Along its floor, which lies as much as $1-2 \mathrm{~km}$ below the surface elevation of the surrounding cap, dunes propagate from the Chasma's interior scarps until they merge with the circumpolar debris that composes the polar erg.

Early estimates of the height of the deposits, based on Mariner 9 radio occultation data, suggested they reached a maximum of $\sim 4-6 \mathrm{~km}$ above the surrounding plains (Dzurisin and 
Blasius 1975). However, more recent and accurate measurements made by the MGS MOLA have revealed that the maximum height of the north polar cap is only $3 \mathrm{~km}$, and that it possesses a complicated, multidomed surface topography (Zuber et al. 1998). Topographic profiles across the northern cap generally show a sharp 1-km increase in elevation between the surrounding terrain and edge of the layered deposits. Large areas on top of the permanent northern ice cap are extremely smooth, with regional slopes over many tens of kilometers of order $0.2^{\circ}$ and with some areas being so smooth that the submeter precision of the instrument on scales of kilometers shows no roughness or slope. The MOLA data also show that the bright outliers that surround the pole are elevated areas, whose local relief varies from tens of meters to well over $1 \mathrm{~km}$. The large areal extent and significant elevation of these deposits argue against them being transient features and support the idea that they are remnants of a previous, more spatially extensive northern ice cap (Zuber et al. 1998, Fishbaugh and Head 1999a). This conclusion is also supported by the preservation of interior deposits within several circumpolar craters, including one that exhibits layering on the same 10-m scale observed in the current polar layered deposits (Garvin et al. 2000).

The northern deposits rest on a very flat plain whose smoothness and low relief has been variously attributed to extensive resurfacing by volcanism (Tanaka and Scott 1987, Smith et al. 1999), an ancient sea bed (Parker et al. 1989, 1993; Scott et al. $1991,1995)$, or the thinly mantled frozen remnant of an ancient ocean (Clifford and Parker 1999). Based on the conservative assumption that the polar deposits have no root beneath the level of the surrounding terrain, the volume of the north polar deposits is estimated to be $1.2( \pm 0.2) \times 10^{6} \mathrm{~km}^{3}$ (Zuber et al. 1998); however, more realistically, isostatic compensation could result in a root of up to $1 \mathrm{~km}$ in depth (Johnson et al. 2000; see also Section 2.4), increasing the estimated volume of the deposits by as much as a third.

In the south, the small residual ice cap ( $\sim 400 \mathrm{~km}$ diameter) is centered at $87^{\circ} \mathrm{S}, 45^{\circ} \mathrm{W}$, a $\sim 200-\mathrm{km}$ offset from the location of the true pole, a relationship whose origin is not currently understood. The residual cap is superimposed on an extensive region of defrosted layered deposits ( $\sim 1500 \mathrm{~km}$ in diameter) whose areal coverage is almost twice that occupied by the equivalent unit in the north. As in the north, the southern deposits appear to be composed of a mixture of ice and dust. Mariner 9 radio occultation data suggested that these deposits reached a maximum thickness of 1-2 km (Dzurisin and Blasius 1975). Viking stereo measurements (Schenk and Moore 2000) and recently acquired MOLA data (Smith et al. 1999) confirm that the thickness of the defrosted layered deposits does indeed average between 1 and $2 \mathrm{~km}$ (Fig. 1d). However, within the area occupied by the residual ice cap, the deposits reach a maximum thickness of $\sim 3 \mathrm{~km}$ above the surrounding terrain. While the thicknesses of the north and south polar deposits appear similar, the differences in their age, areal extent, and mass distribution about their respective poles is substantial, and may well be related to the $\sim 6-\mathrm{km}$ higher elevation of the south polar highlands over the northern plains (Smith et al. 1999).

The north and south polar deposits also differ in their apparent thermal inertia and surface roughness. The comparatively high inertia of the northern deposits is consistent with the widespread exposure of water ice at the surface (Paige et al. 1994); while the lower inertia of the southern deposits is indicative of a surface covered by a mantle of fine-grained material of unknown thickness (Paige and Keegan 1994, Vasavada et al. 2000). One possible explanation for this difference is that, over the $\sim 100 \mathrm{x}$ greater exposure age of the southern deposits, the sublimation of ice from the surface has resulted in the formation of a finegrained lag deposit. In contrast, the higher thermal inertia of the northern deposits indicates a younger, more rapidly evolving surface-where deposition, erosion, or a combination of both has maintained a fresh exposure of ice-rich material. This last possibility is consistent with models of the evolution of the polar troughs, where the higher insolation experienced by the equatorward-facing scarps has led to preferential erosion, while deposition is believed to have been dominant on the poleward faces and the elevated flats between neighboring troughs (Howard et al. 1982; Howard 2000; Fisher 1993, 2000).

Interestingly, Earth-based radar observations show that the martian south polar residual ice cap is highly reflective at $3.5 \mathrm{~cm}$ wavelength, with many scattering centers (cracks or voids) in the upper $10 \mathrm{~m}$. These scattering centers are likely distributed in a very low loss medium (Butler 1994, Muhleman et al. 1995), perhaps indicative of nearly pure water or $\mathrm{CO}_{2}$ ice. Similar radar data show that the north polar layered deposits are not highly reflective and probably not cracked. These findings may reflect differences in the near-surface vertical density profiles of the north and south caps. If the caps have grown by the deposition of material with the physical characteristics of terrestrial snow, then its densification in response to Mars' low gravity should be slow, creating the equivalent of a terrestrial firn layer (where the density of the deposits is less than that of ice) as much as several hundred meters deep. However, this expectation seems at odds with the radar data in the south. This conflict may be resolved by recent work that suggests that thermally induced vapor diffusion, combined with low accumulation rates and high summer temperatures, may rapidly metamorphose an initially snow-like deposit into solid ice at the surface of the cap (Arthern et al. 2000).

While the low thermal inertia and greater age of the south polar deposits imply a reasonably stable surface, high-resolution images have revealed that, in some areas, the surface of the deposits is grooved-suggesting they have undergone recent eolian erosion (Cutts 1973). However, at other locations, the burial of secondary craters indicates that deposition has also occurred in the recent past (Howard et al. 1982, Herkenhoff 2000). Thus, the geologic history of the layered deposits at both poles appears to have been complex.

Similar to its northern counterpart, one of the most notable features of the southern cap is a pattern of comparatively dark 
equatorward-facing scarps that spiral clockwise and outward from the pole. But whereas, in the north, virtually all of the defrosted scarps are actually the sunward-facing walls of nearly symmetric troughs (Zuber et al. 1998), in the south, most are true scarps-unopposed by a corresponding poleward-facing trough wall (Dzurisin and Blasius 1975, Smith et al. 1999, Schenk and Moore 2000). There are also several major erosional reentrants within the defrosted layered deposits. The largest of these, Chasma Australe $\left(88^{\circ} \mathrm{S}, 270^{\circ} \mathrm{W}\right)$, has roughly the same general scale and shape as Chasma Boreale in the north, but with a more radial, or longitudinal, orientation.

\subsection{Seasonal and Climatic Evolution}

While many details are uncertain, a general consensus has developed regarding the constructional processes responsible for the origin of the polar layered deposits. An essential element of this model is the belief that atmospheric dust, raised by local and global dust storms, acts as nucleation centers for $\mathrm{H}_{2} \mathrm{O}$ ice condensation. As either hemisphere enters the fall season, these suspended particles receive an additional coating of frozen $\mathrm{CO}_{2}$ that makes them heavy enough to precipitate from the atmosphere, thus contributing to the growth of both the seasonal and permanent caps (Cutts 1973, Pollack et al. 1979).

Observational support for this depositional model came from Viking Lander $2\left(48^{\circ} \mathrm{N}, 225.6^{\circ} \mathrm{W}\right)$ which returned images that revealed the sudden appearance of a reddish-tinted "snow" during the northern fall (Jones et al. 1979, Wall 1981, Guinness et al. 1982). This thin snow cover persisted throughout the northern winter and became patchy by early spring. However, it was not until many weeks after surface temperatures had risen above the $\mathrm{CO}_{2}$ frost point that all the condensate finally disappeared, leaving behind a thin veneer of dust. This observation confirms the existence of an $\mathrm{H}_{2} \mathrm{O}$ ice component within the seasonal deposit.

The ultimate fate of the dust and $\mathrm{H}_{2} \mathrm{O}$ that precipitates from the atmosphere during the formation of the seasonal cap is a function of the latitude at which final deposition occurs. At the very highest and coldest latitudes, where $\mathrm{H}_{2} \mathrm{O}$ ice is in equilibrium with the water vapor in the atmosphere, the ice-rich depositional layer persists throughout the year, thus adding to the perennial cap. However, at those latitudes where diurnal temperatures rise above the frost point, any surface $\mathrm{H}_{2} \mathrm{O}$ sublimes away. What remains is a thin (micrometers thick) seasonal mantle of dust that extends from the periphery of the polar caps down to $\sim 40^{\circ}$ latitude. In some regions there is evidence that local winds episodically remove and redistribute this eolian deposit (Arvidson et al. 1983), while in other regions it may accumulate from year to year, forming a blanket of debris that covers the local terrain (Soderblom et al. 1973).

If this precipitation model is correct, then the large-scale layering exposed in the polar troughs suggests that the depositional and erosional balance at the poles has been modulated by periodic variations in insolation due to changes in the martian obliq- uity and orbital elements (Murray et al. 1972, Toon et al. 1980, Cutts et al. 1981; Cutts and Lewis 1982). The presence of both large- and fine-scale layering suggests that mechanisms operating on many different timescales are required to explain the polar stratigraphy. Of these, the martian obliquity exerts the greatest influence. The obliquity oscillates about its current mean value with a period of $1.2 \times 10^{5}$ years. The amplitude of this oscillation also varies and is modulated with a period of $1.3 \times 10^{6}$ years (Ward 1992). At low obliquity, both seasonal temperature fluctuations and mean annual polar temperatures are at a minimum. This situation is reversed at times of high obliquity, when summers of continuous illumination alternate with dark winters, to produce both extreme seasonal variations and higher mean annual temperatures at the poles.

Other astronomical variables affecting polar insolation include the $5.1 \times 10^{4}$ year precessional cycle and two superposed periods of change in orbital eccentricity, a $9.5 \times 10^{4}$ year cycle with a peak-to-peak amplitude of 0.04 , and a $2 \times 10^{6}$ year cycle with an amplitude of 0.1 (Murray et al. 1973, Ward 1979, Toon et al. 1980). However, while the precessional cycle and variations in orbital eccentricity affect the peak value and duration of summer polar insolation, only changes in obliquity actually alter the mean annual insolation at a given latitude.

Despite this knowledge, our ability to calculate the insolation history of Mars is limited by two effects. First, recent studies have demonstrated that, due to a gravitational resonance with the orbit of Venus, the evolution of the martian obliquity is chaotic, varying from $\sim 0^{\circ}$ to $60^{\circ}$ (Touma and Wisdom 1993, Laskar and Robutel 1993). This behavior places an upper limit of several million years on how far back (or forward) the present obliquity can be reliably extrapolated. Second, the total mass of the polar caps, and any asymmetry in the distribution of that mass around the pole (e.g., as evident in the south), can influence the rate of precession and induce polar wander. Thus, there is a significant potential for climate feedback on polar insolation - the principal driver of climate change (Bills 1999).

Astronomically driven temperature variations can affect the evolution of the polar terrains in several ways. For example, the cold polar temperatures that characterize low obliquities may result in the equatorward advance of the polar terrains by as much as several degrees. By the same token, the warmer temperatures associated with high obliquities should shift these borders closer to the poles (Toon et al. 1980). This suggests that the current polar boundaries are only a surface manifestation of the present insolation balance; therefore, at depth, they may be interbedded over considerable distances (Squyres 1979).

In addition to modulating the areal extent of the polar deposits, climatic variations can also influence the quantity of material that is deposited and retained by the caps. For example, at low obliquity, when the poles are at their coldest, large $\mathrm{CO}_{2}$ ice caps should persist throughout the year. In that event, atmospheric pressure may fall to the point where dust can no longer be elevated from the planet's surface (Toon et al. 1980, Fanale et al. 1982). This cessation of dust storm activity could drastically 
reduce or eliminate $\mathrm{H}_{2} \mathrm{O}$ deposition at the poles. So too, at times of high obliquity, sublimation due to high polar surface temperatures may substantially reduce or eliminate the $\mathrm{H}_{2} \mathrm{O}$ component of the annual depositional layer (Toon et al. 1980, Fanale et al. 1982). Therefore, significant polar accumulation may occur only under climatic conditions similar to those we observe at present.

There is, however, a notable exception to this scenario if dust particles are not the principle agents for bringing water to the poles. At low obliquity, the resulting colder temperatures at the poles will result in the formation of perennial $\mathrm{CO}_{2}$ ice caps. However, since it is unlikely that both poles will have the same annual energy budget, the $\mathrm{CO}_{2}$ will eventually migrate to the most efficient cold trap. Thus, over time, one pole will win outforming a single permanent $\mathrm{CO}_{2}$ ice cap that will also act as the dominant cold trap for atmospheric water vapor. In this way, even at times of low obliquity, water vapor arising from the diffusive instability of ground ice at low latitudes, or released to the atmosphere by volcanism, impacts, and catastrophic floods might accumulate at the poles in significant quantities (Toon et al. 1980).

Which pole retains a permanent $\mathrm{CO}_{2}$ cap depends on its heat balance. To first order the key difference between the two poles is topography - through its effect on the $\mathrm{CO}_{2}$ frost point temperature and the winter heat balance (since the total insolation available in the summer seasons to sublimate $\mathrm{CO}_{2}$ is the same at both poles, for a given obliquity; Toon et al. 1980). The north pole is $\sim 6.5 \mathrm{~km}$ lower than the south pole (Smith et al. 1999). This elevation difference yields a $5.8-\mathrm{K}$ difference in the surface condensation temperature of $\mathrm{CO}_{2}(149 \mathrm{~K}$ in the north versus $143.2 \mathrm{~K}$ in the south). It also results in a $14.8 \%$ higher $\mathrm{CO}_{2}$ condensation rate in the north versus the south, assuming a transparent atmosphere (Forget and Pollack 1996). Thus, on this basis, the north pole is the favored pole for a permanent $\mathrm{CO}_{2}$ ice cap since it radiates at a higher surface temperature and should therefore accumulate more $\mathrm{CO}_{2}$ ice during winter than the south cap. In the present epoch, this effect is partially offset by the $20 \%$ shorter duration of the northern winter-a relationship that changes with time due to the planet's $5.1 \times 10^{4}$ year precessional cycle and high (0.0934) orbital eccentricity (Ward 1979, Toon et al. 1980). However, this fact alone does not explain the present-day situation where the south pole is the one that retains a permanent covering of $\mathrm{CO}_{2}$ ice.

The survival of the southern $\mathrm{CO}_{2}$ cover has been attributed to a spring albedo approximately $33 \%$ higher than observed during the equivalent season in the north (Paige and Ingersoll 1985). Paige and Kieffer (1986) suggest that this hemispheric asymmetry is the result of the greater insolation received during southern spring, which occurs near perihelion. They argue that the rapid heating of dust grains entrained in the seasonal deposit causes them to sink into the frost, increasing the albedo sufficiently to preserve $\mathrm{CO}_{2}$ throughout the southern summer. Kieffer et al. (2000) have proposed an alternative mechanism whereby the rapid sublimation of the seasonal $\mathrm{CO}_{2}$ cap in the early spring produces a wind whose upward velocity component exceeds the Stokes-Cunningham settling velocity of atmospheric dust grains. In this way, as the sublimation rate increases due to the higher spring insolation, progressively larger dust grains are lofted and transported off the seasonal cap.

Another potential contributing factor to the higher albedo of the south polar ice cap is that the atmospheric dust load is currently the greatest when the north seasonal cap is forming, which occurs near the perihelion peak in dust storm activity. Thus, the north cap is expected to be darker than the south cap. Unfortunately, observations of the seasonal cap albedos are not complete enough to determine if this is actually the case. Interestingly, models of the seasonal variation in $\mathrm{CO}_{2}$ surface pressure seem to require seasonal cap albedos that are brighter in the north than in the south, or at the very least no different between the two hemispheres. A key question of considerable importance in relation to the formation of the polar layered terrains is whether global dust storms occur in northern summer during epochs when this is within the perihelion season-resulting in the transport and incorporation of large amounts of dust into the southern seasonal and residual caps. Or is there instead an asymmetry between the two hemispheres in this regard? Circulation modeling studies (Haberle et al. 1993, Barnes et al. 1993, 1996) suggest that the large difference in topography between the two hemispheres has a very large effect on the circulations in the different seasons, and it is possible that this might limit the occurrence of global dust storms during northern summer - except, perhaps, at higher obliquities, when a denser atmosphere would tend to strongly enhance dust storm activity (Kieffer and Zent 1992).

A similar statement can be made regarding the cap emissivities. In order to match the Viking Lander pressure data, models need to suppress the emissivity of the north cap relative to the south cap. A reduced emissivity could be due to the unusual properties of pure $\mathrm{CO}_{2}$ ice crystals on the surface, or to the observed presence of $\mathrm{CO}_{2}$ ice clouds in the atmosphere (Bell et al. 1996, Hansen 1999, Kieffer et al. 2000).

Laboratory studies, as well as TES and MOC observations, suggest that the thermophysical and radiative properties of $\mathrm{CO}_{2}$ are contributing to a seasonal polar cap behavior more complex than previously imagined (Hansen 1999, Kieffer et al. 2000, James et al. 2000). As the seasonal south polar cap receded during the first southern spring observed by the Mars Global Surveyor, a prominent and variegated dark region developed within the cap $\left(\sim 75^{\circ}-85^{\circ} \mathrm{S}, 150^{\circ}-310^{\circ} \mathrm{W}\right)$ that had an albedo similar to that of bare martian soil but a surface temperature that, while several degrees warmer than the surrounding cap, remained too cold to be ice-free. TES observations revealed a weak spectral emission depression near the $25-\mu \mathrm{m}$ "transparency" band of $\mathrm{CO}_{2}$ indicating an average scattering length in solid $\mathrm{CO}_{2}$ of centimeters or more.

These unusual characteristics led the TES team to dub this area the "Cryptic" region and prompted a reexamination of the Viking IRTM data for any evidence of a previous occurrence. This analysis demonstrated that the Cryptic region is a 
repeatable phenomenon, occurring at roughly the same time and location every year. Further investigations have shown that the north seasonal cap displays similar Cryptic-like characteristics in some regions in the spring.

TES and laboratory data suggest that the low albedo and temperatures associated with the Cryptic region may result from the development of solid $\mathrm{CO}_{2}$ ice (vs the snow or frost generally associated with seasonal cap). However, it is unclear whether the low albedo of the Cryptic material results from dust dispersed in very coarse-grained $\mathrm{CO}_{2}$ or whether the $\mathrm{CO}_{2}$ is so transparent that it reveals the dark soil that lies underneath.

Observations of the north polar winter cap have also revealed sporadic "cold spots" similar to those observed in the south by the Viking IRTM (Kieffer 1979, Hansen 1999, Weiss and Ingersoll 2000). Occasional "super-cold" spots have been seen with $25-\mu \mathrm{m}$ brightness temperatures as low as $115 \mathrm{~K}$ (spectral emissivities $\sim 0.1$ ) ; yet, brightness temperatures at $18 \mu \mathrm{m}$ appear consistent with expected kinetic surface temperatures. One possible explanation for these observations is that atmospheric $\mathrm{CO}_{2}$ becomes locally depleted near the surface, dramatically lowering its condensation temperature (Kieffer 1979, Weiss and Ingersoll 2000). Alternatively, TES spectral observations suggest that these cold spots are largely caused by the radiative properties of unusually fine-grained $\mathrm{CO}_{2}$, whose deep emission depression at $25 \mu \mathrm{m}$ could well explain the less-than-unity effective emissivity required by modeling studies of the seasonal polar caps to match the observed annual surface pressure variation (Hansen 1999).

Although the TES observations are providing important insights, the processes controlling the current $\mathrm{CO}_{2}$ cycle (i.e., the albedo and emissivity of the caps, the coupling to the dust and water cycles, and the role of atmospheric heat transport) are not yet well understood. Clearly, if we are to understand how the martian climate system responds to changes in orbit parameters, it is imperative that we understand the processes controlling the present system. In this sense, the key to the past lies in the present.

\subsection{Geothermal and Hydrologic Evolution}

The martian cryosphere has been defined as that region of the crust where the temperature remains continuously below the freezing point of water (Fanale 1976, Rossbacher and Judson 1981, Kuzmin 1983). Assuming a solute-free freezing point of $273 \mathrm{~K}$, this condition is satisfied at the surface at every latitude below the diurnal skin depth. At depth, the location of the base of the cryosphere is determined by the latitudinal variation of mean annual surface temperature, the thermal conductivity of the crust, and the value of the geothermal heat flux. Based on reasonable estimates of the globally averaged values of these properties, the present thickness of frozen ground on Mars is thought to vary from $\sim 2.5-5.0 \mathrm{~km}$ at the equator to $\sim 6.5-13 \mathrm{~km}$ at the poles (Clifford 1993).

Because crustal water will diffuse from regions of higher to lower temperature in response to the geothermally induced gradient in vapor pressure, the pore space within the cryosphere acts as a cold-trap for any water present in the crust (Clifford 1993). In light of this behavior, and the $0.5-1 \mathrm{~km}$ estimate of the planet's inventory of water (Carr 1986), it is likely that much of the pore volume of the cryosphere is saturated with ice-at least near the poles (Fig. 3a).

Given the conditions above, the preferential deposition of dust and $\mathrm{H}_{2} \mathrm{O}$ at the polar surface will result in a situation where the equilibrium depth to the melting isotherm has been exceeded. In response to this added layer of insulation the position of the melting isotherm will rise within the crust until thermal equilibrium is reestablished. By this process, any ice within the intervening pore space will melt and drain to saturate the lowermost porous regions of the crust (Fig. 3b). Should deposition continue, the deposits may ultimately reach the required thickness for melting to occur at their actual base (Clifford 1987). Under such conditions, the deposits may reach a state of equilibrium - where the deposition of any additional ice at the surface is offset by the melting of an equivalent layer at the base of the cap (Fig. 3c).

Under present conditions, it is estimated that the polar deposits would have to be $\sim 6.5-13 \mathrm{~km}$ thick for melting to occur at their actual base (i.e., Fig 3c; see also Clifford 1993). This suggests that the current position of the melting isotherm lies at least several kilometers beneath the base of the deposits (Fig. 3b) -its exact location being dependent on the mean annual surface temperature $(\sim 155 \mathrm{~K})$, local geothermal heat flux, thermal conductivity of the deposits, and melting temperature of the polar ice (which may be depressed below $273 \mathrm{~K}$ by the effect of pressure and the presence of freezing-point depressing salts). Should glacial sliding occur, the resulting frictional heat could substantially reduce this thickness. For example, a sliding velocity of $10 \mathrm{~m} \mathrm{yr}^{-1}$, driven by a basal shear stress of $100 \mathrm{kPa}$ (a value typical of terrestrial glaciers and ice sheets), produces sufficient heat $\left(\sim 30 \mathrm{~mW} \mathrm{~m}^{-2}\right)$ to halve the thickness of polar ice required for basal melting during the present epoch (Clifford 1987). Given the higher geothermal heat flux that is thought to have characterized the planet's early history (e.g., up to 5-6 times greater $4 \mathrm{Ga}$ ago; Schubert et al. 1992), the conditions for basal melting were almost certainly more favorable in the past. Indeed, Clifford (1993) and Clifford and Parker (1999) have argued that this process may have played a critical role in the climatic cycling of water on Mars-providing a mechanism whereby groundwater that was discharged to the surface during the development of the valley networks and outflow channels may have been reintroduced into the subsurface to replenish the global aquifer from which it was originally withdrawn.

Possible evidence of past basal melting has been discussed by several investigators. For example, in Dorsa Argentea $\left(78^{\circ} \mathrm{S}\right.$, $40^{\circ} \mathrm{W}$, Fig. 4) - a region that lies just beyond the outer periphery of the south polar layered deposits-there is an extensive network of sinuous and braided ridges that resemble terrestrial eskers (Howard 1981, Kargel and Strom 1992, Metzger 1992). Eskers result from the deposition of fluvial sediments in subglacial rivers and streams that are associated with glaciers and 


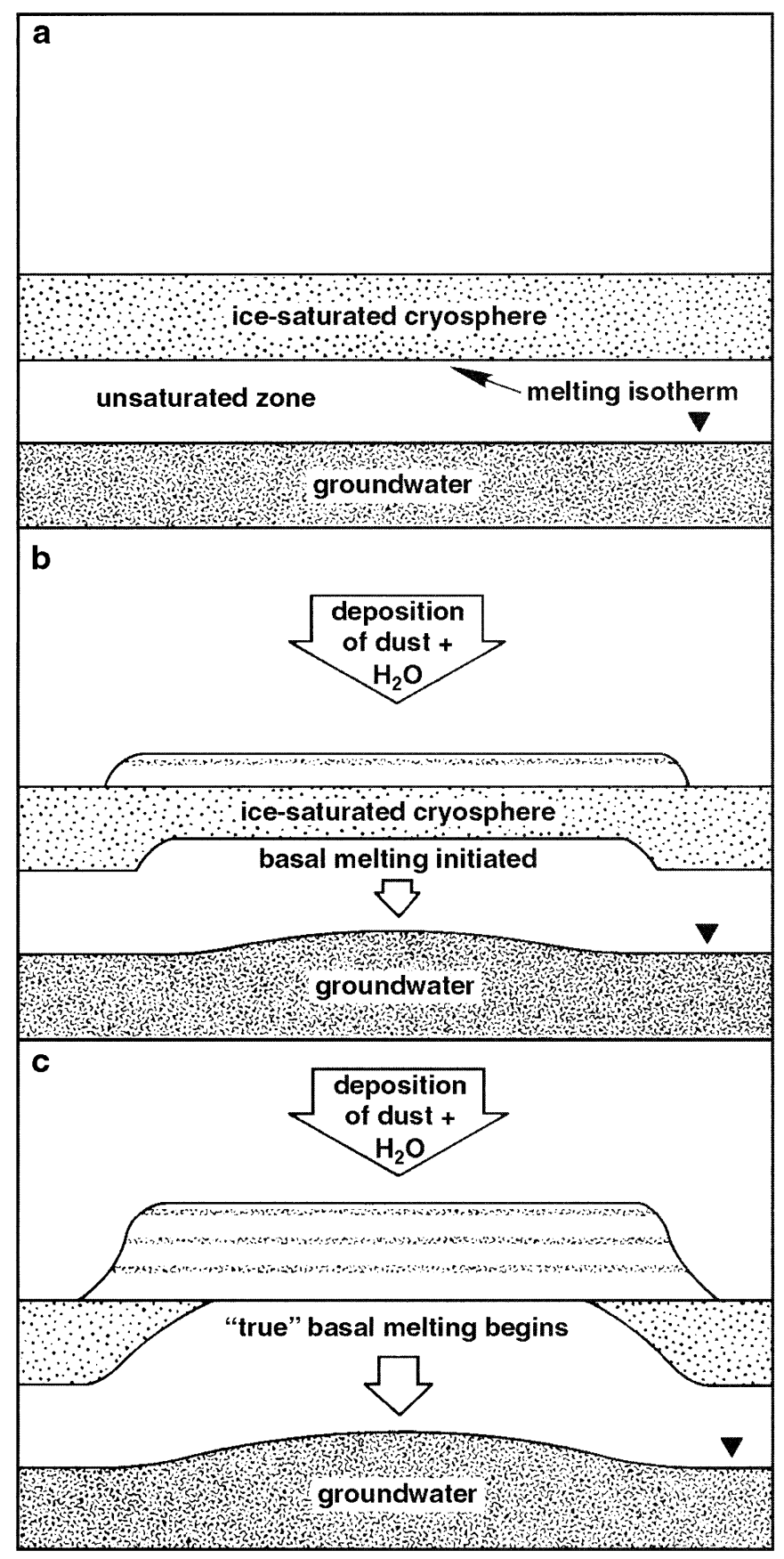

FIG. 3. An idealized cross section of the martian polar crust illustrating the possible time evolution of polar basal melting (Clifford 1987, 1993). The sequence depicts (a) a time prior to the deposition of any dust and ice, (b) the onset of deposition and basal melting, and (c) melting at the actual base of the deposits. Given reasonable estimates of the present thickness, thermal conductivity, geothermal heat flow, and mean annual surface temperature of the north and south polar deposits, it is likely that the current position of the melting isotherm lies as much as several kilometers below the base of the deposits (as illustrated by b). However, given the theoretical expectation of a previously higher planetary heat flow (Schubert et al. 1992) and the geomorphic and topographic evidence that the deposits were once more extensive (Zuber et al. 1998, Smith et al. 1999), it appears that the potential for true basal melting (i.e., c) was significantly greater in the past. ice sheets that have undergone significant melting. On Mars, the occurrence of such features outside the area occupied by the south polar deposits implies that either these deposits were once more extensive (e.g., Tanaka 2000), or that the sinuous and braided ridges were formed by some other process. Alternative modes of ridge origin include periglacial action involving icerich regolith (Howard 1981, Metzger 1992), inverted channels due to erosionally resistant indurated alluvial stream deposits (Rice 1994), eolian modification of dust deposits (Ruff 1994), and lava flows (Tanaka and Scott 1987).

It has been suggested that subglacial discharges may have also contributed to the formation of the major polar reentrants, including Chasma Boreale in the north and Chasma Australe in the south, as well as a number of similar, but smaller features found along the periphery of both caps (Wallace and Sagan 1979, Clifford 1987, Benito et al. 1997, Fishbaugh and Head 1999b, Anguita et al. 2000). These broad, linear, and deeply incised depressions may have originated from a jökulhlaup, the catastrophic discharge of a large subglacial reservoir of basal meltwater. A terrestrial example of this process is the recurrent catastrophic drainage of Grimsvötn, a subglacial lake near the center of the Vatnajökul ice cap in Iceland (Björnsson 1974, Nye 1976). On Mars, the accumulation of large reservoirs of basal meltwater may have occurred in response to either a high regional geothermal heat flow or the existence of localized hot spots (e.g., associated with near-surface igneous intrusions or subglacial volcanic eruptions). Alternatively, Howard $(1978,2000)$ and Howard et al. (1982) suggest that the reentrants and chasmata may originate from katabatic winds draining from the polar cap, which may directly erode the polar deposits or enhance ice ablation rates. Whether they were formed by endogenic or exogenic processes, the general similarity in the size, orientation, and morphology of Chasma Boreale and Chasma Australe argues for a common origin. High-resolution imaging and laser altimetry by $M G S$ are providing important new data that should help clarify various elements of this debate; however, a definitive resolution appears unlikely without complementary or corroborating in situ field investigations.

\subsection{Rheologic Properties and the Origin of the Polar Troughs}

When ice is subjected to an applied stress it deforms at a rate that is a function of the magnitude of the stress, the temperature of the ice, the size and orientation of the ice crystals, and the volumetric content, distribution, and composition of impurities (Paterson 1981). In a glacier or ice cap, the stress that drives the deformation and flow of ice is equal to the product of the local slope of its surface and the hydrostatic pressure exerted by its local thickness. Theoretical and field studies of terrestrial glaciers indicate that virtually all of the deformation associated with glacial flow occurs at the ice sheet's base, where the temperature and shear stress are greatest. On Earth, the various parameters that govern flow are readily assessed by a combination of in situ measurements and remote sensing. On Mars, however, many of these properties are still unknown. Fortunately, new 


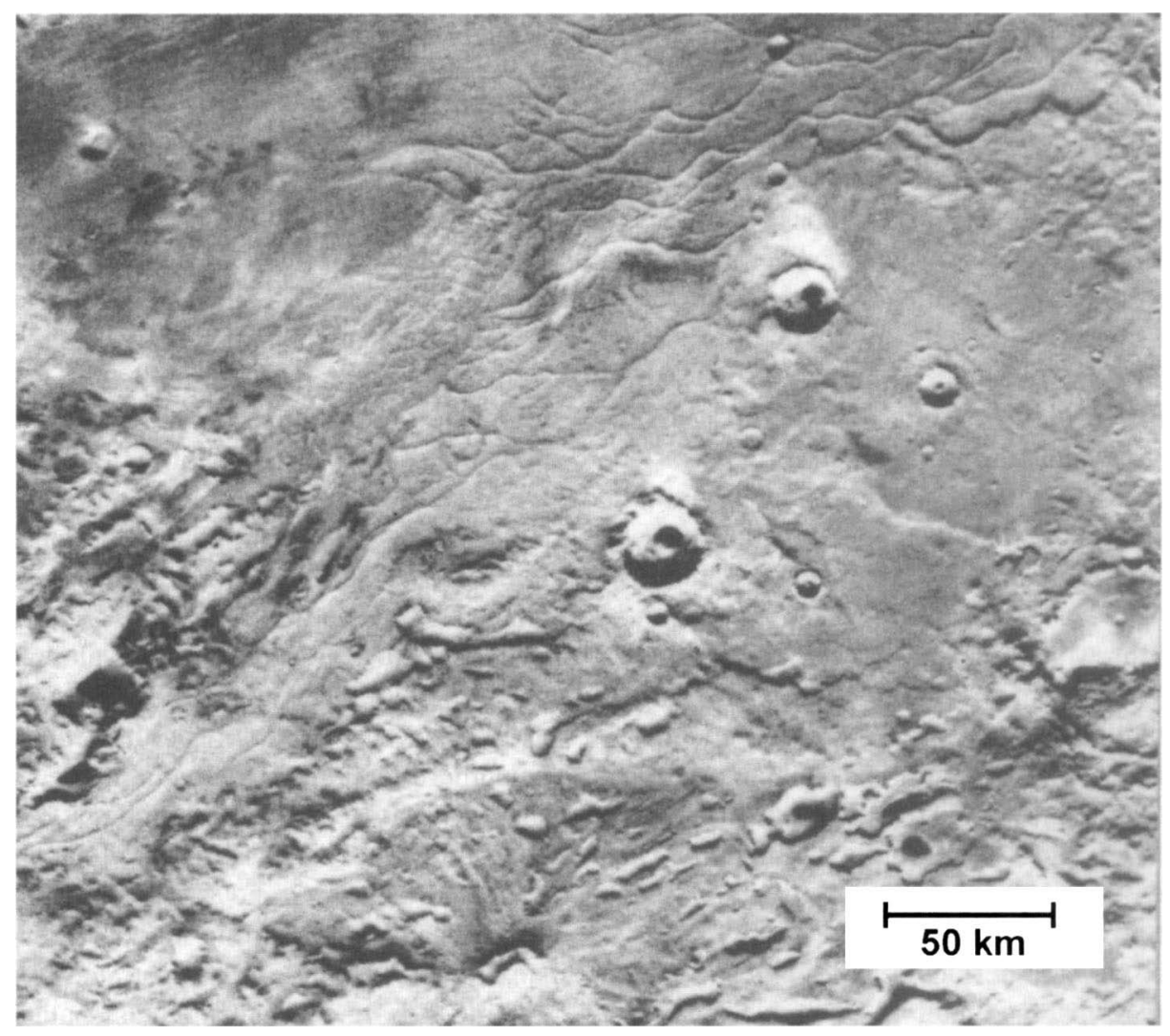

FIG. 4. Braided ridges in the Dorsa Argentea region $\left(77^{\circ} \mathrm{S}, 44^{\circ} \mathrm{W}\right)$ that have been interpreted as possible eskers (Howard 1981, Kargel and Strom $1992 ;$ Viking Orbiter frame 421B14). If this interpretation is correct, it indicates that the south polar deposits were more extensive in the past.

results from $M G S$, the reanalysis of Viking images, and recent laboratory work on the deformation of ice under martian conditions are beginning to provide long-awaited answers to some fundamental questions.

As noted earlier, MOLA measurements indicate that the north polar cap rises $\sim 3 \mathrm{~km}$ above the surrounding plain (Smith and Zuber 1998, Zuber et al. 1999). A terrestrial ice cap this large would be isostatically compensated by a keel whose maximum depth beneath the cap would be proportionate to the product of the cap's height times the ratio of the bulk density of the polar ice to the bulk density of the crust $(\sim 1 / 3)$ (Nye 1959, Johnson et al. 2000). Although the crustal density of Earth and Mars is likely to be similar, the uncertainty in the amount of dust entrained in the martian polar ice results in a corresponding uncertainty in bulk density-with plausible values ranging from $\sim 10^{3}$ to $2 \times 10^{3} \mathrm{~kg} \mathrm{~m}^{-3}$. The high levels of water vapor observed over the cap during the northern summer. Confirm that the composition of its volatile component is water ice. This suggests that the two greatest factors affecting the rheology of the northern cap, compared with its terrestrial counterparts, are likely to be the $\sim 100 \mathrm{~K}$ lower mean annual surface temperature and the effect of an unknown, but potentially large (1-50+\%), volumetric fraction of embedded micrometer-sized dust.
Given the low temperatures and lack of water vapor detected over the south polar cap during the Viking mission, there has been much speculation regarding whether the primary ice component of that cap is $\mathrm{CO}_{2}$. However, recent lab work (Durham et al. 1999) indicates that the strength of $\mathrm{CO}_{2}$ ice under ambient martian conditions prohibits the development of a $\mathrm{CO}_{2}$ ice cap thicker than about $1 \mathrm{~km}$ (Nye et al. 2000). This conclusion is reinforced by consideration of the thermal properties of $\mathrm{CO}_{2}$, whose low thermal conductivity $\left(\sim 1 / 5-1 / 6\right.$ that of $\mathrm{H}_{2} \mathrm{O}$ ice at an equivalent temperature) places a similar limit on the thickness of a $\mathrm{CO}_{2}$ cap due to basal melting (Mellon 1996, Ross and Kargel 1998). These results are important because the central portion of the south polar cap is $\sim 3 \mathrm{~km}$ high, thus excluding $\mathrm{CO}_{2}$ as its primary constituent. For this reason, Nye et al. (2000) conclude that the south cap must be composed of a mixture of water ice and dust (and possibly water ice- $-\mathrm{CO}_{2}$ clathrate) in some as yet unknown proportions.

A considerable amount of laboratory work remains to be done on the rheology of the possible mixtures of ice, dust, and salt that may be present in the caps. To date, the most comprehensive data on the creep of water ice under various conditions of temperature, pressure, and particulate content are that compiled by Durham et al. (1997a,b). A significant concern in interpreting 
the results of such analyses is their validity when extrapolated to the very low strain rates appropriate to Mars. Even in terrestrial glacial studies, where ice deformation rates are substantially enhanced by the $\sim 100 \mathrm{~K}$ higher mean annual temperatures, the difference between the strain rates that can realistically be investigated in the lab and those that actually occur in the field is a significant problem. This problem is orders of magnitude more acute on Mars, where estimated accumulation rates on the order of $\sim 10^{-4} \mathrm{~m} \mathrm{yr}^{-1}$ and surface temperatures as low as $\sim 140$ $155 \mathrm{~K}$ yield horizontal strain rates of as small as $\sim 10^{-8} \mathrm{yr}^{-1}$.

Temperature and mass balance are two of the most significant factors affecting flow. Given a present mean annual surface temperature of $155 \mathrm{~K}$ and a geothermal gradient of $15^{\circ} / \mathrm{km}$, the temperature at the base of the north polar cap likely falls between 200 and $215 \mathrm{~K}$. This bed temperature, combined with the cap's observed range of surface slopes, is sufficient to support flow velocities of as much as a few centimeters per year (Fisher 2000). Of course, if the long-term temperature environment changes, so too will the potential for flow.

Small terrestrial glaciers have a natural mass-balance averaging interval of 1-10 years. However, for large ice sheets, like Antarctica and Greenland, it can be centuries to millennia. During the colder part of this interval the ice caps and glaciers accumulate and their flow velocities are at a minimum; conversely, during the hot ablation period their velocities are often at a maximum. The mass-balance interval most relevant to the martian ice caps is the obliquity cycle $\left(\sim 1.25 \times 10^{5} \mathrm{yr}\right)$, where ice accumulates during the cold part of the cycle and ablates (and possibly flows) during the warm part. Because the martian obliquity varies chaotically (Touma and Wisdom 1993, Laskar and Robutel 1993), the potential exists for substantial changes in surface temperature. However, these changes are attenuated rapidly with depth, yielding temperature fluctuations of only $\sim 5-10 \%$ at a depth of 3-4 km. Due to the sensitive temperature dependence of the flow law, even such small changes could have a considerable impact on the rheologic evolution of the caps; although, given the time required for the thermal wave to propagate through the deposits, the basal response of the caps to climate change could lag 30-70 Kyrs behind the conditions experienced at the surface (Larsen and Dahl-Jensen 2000).

Most large terrestrial ice caps are generally characterized by a broad central region of accumulation and a relatively small peripheral ablation area-having profiles that are well described by a "power 3 flow law" (Paterson 1981). In such instances, variations in the surface relief of the cap can be directly related to both its mass-balance history and basal topography. However, thin cold-based ice caps often deviate from this ideal and have surface slopes determined by their mass balance profile alone. On Mars, the polar caps exhibit a complex accumulation and ablation regime that consists of a small inner zone of pure accumulation and an outward-spiraling pattern of alternating low-albedo ablation and high-albedo accumulation zones.

Howard $(1978,2000)$ and Howard et al. (1982) suggest that the spiral pattern of troughs in the north and scarps in the south originate near the edge of the polar deposits and then migrate, by the preferential sublimation of ice from their sunward-facing scarps, toward the pole. This loss of ice may be influenced by interactions with off-pole katabatic winds whose flow is deflected by Coriolis forces and crosses the troughs at nearly right angles. Dust liberated by this process may then be scavenged by the winds and redistributed over the planet, while the sublimed ice may simply be recycled by cold-trapping on the poleward facing slopes and flats that separate the troughs.

Fisher $(1993,2000)$ has dubbed the spatially overlapping relationship of accumulation and ablation that occurs within the polar deposits as "accublation" and has proposed an alternative model for the origin of the troughs and scarps involving a combination of accumulation, ablation, and flow. The accublation model (Fisher 1993, 2000) proposes that ice flows from the white frosted regions, which are accumulating ice, toward the darker equatorward-facing scarps along the troughs, which are losing mass. This results in the migration of the ablation scarps on the surface of the moving ice until they reach a location where their migration velocity is equal to the flow velocity of the ice. The model suggests that the spiral pattern of troughs, scarps, and reentrant valleys results from the nonsymmetric distribution of the ice flow centers and associated velocity fields around the pole. Because of its strong model dependence, this conclusion is extremely tentative-as illustrated by such fundamental uncertainties as the thermal and mass-balance histories of the caps and the numerical value of the exponent in the flow law.

But the case for significant flow appears to suffer from at least one inconsistency. When the surface slopes of the north polar cap are averaged over distances that are $\sim 10 \times$ the cap's estimated local thickness (a standard scaling and averaging relationship used in terrestrial glaciology, e.g., Paterson 1981) it suggests a yield stress in the range of $50-200 \mathrm{kPa}$, a value appropriate for water ice. In contrast, the slopes of the scarps that bound the polar troughs are as much as 10 times greater, yet they exhibit no obvious evidence of closure by flow. One explanation for this may be that the surface temperatures within the troughs are so cold that the near-surface ice is simply too stiff to deform. If so, then it suggests that the shape of the troughs is maintained almost solely by ablation processes. While the elevation data provided by MOLA have clearly defined the three-dimensional structure of the troughs, as well as the variation in their relative depth as a function of their geographic position within the cap, this information alone cannot resolve the question of flow without an accurate knowledge of the long-term and spatially variable ablation and deposition rates within the cap.

The question of flow also has important ramifications for understanding the continuity and age of the polar cap's layered stratigraphy. For example, according to the accublation flow model, the material visible in the upper layers of the polar scarps was precipitated locally, while the material present in the lower layers was originally precipitated in the cap's interior. This model predicts that the combination of local deposition, trough topography, and the radial flow of the cap will result in 
discontinuities between the locally derived younger layers and the interior-derived older layers, an observation that should be most notable on the outermost scarps. For this reason, one would expect the old, lower layers to be more regular and traceable over long distances than the younger, upper layers.

Angular unconformities, indicative of a complex history of erosion and deposition, have been recognized in the north polar layered deposits (Cutts et al. 1976, 1979; Howard et al. 1982) but not yet in the south, where Viking Orbiter image resolution is poorer. High-resolution MOC images of both polar regions are allowing such structural relations to be studied in more detail, raising the possibility that angular unconformities may be discovered in the south polar layered deposits as well.

Waves in the polar strata are another expected consequence of the accublation flow model (Fisher 2000). Such waves originate because the particle paths under accumulation zones move downward, while in ablation zones they move upward. The resulting wavelength depends on the ratio of the ablation-induced scarp velocity to the ice velocity of the deforming cap-the higher the ratio, the shorter the wavelength. On the other hand, a completely stagnant ice cap should result in horizontal layers with little or no deformation; thus, they should be traceable over long distances no matter what their depth in the polar stratigraphy.

\subsection{The Geologic Evidence for and against Glacial Flow}

Various lines of evidence suggest that ice may have played a more extensive role in the geomorphic evolution of the martian surface in the past, including at the poles (Tanaka 2000, Garvin et al. 2000). Products of volcano-ice interactions appear to be widespread, especially at mid-latitudes (Allen 1979, Hodges and Moore 1979, Rossbacher and Judson 1981, Mouginis-Mark 1985, Squyres et al. 1987, Christiansen 1989, Chapman 1994, Garvin et al. 2000). Other terrains appear to have been formed by ice-assisted mass wasting, ablation, and other types of periglacial activity (Carr and Schaber 1977, Howard 1981, Lucchitta 1981, Squyres and Carr 1986, Costard and Kargel 1995). Although the interpretation of specific features is often debated, there is a substantial consensus that periglacial processes (involving regolith creep, rock fracturing by freeze-thaw, and related processes) have been important in the geomorphic development of the surface. More controversial are proposals that true glacial processes (involving thick, self-deforming ice sheets) were widespread on Mars (Lucchitta 1982, Battistini 1987, Tricart 1988, Baker et al. 1991, Kargel and Strom 1992, Kargel et al. 1995). This is especially true of paleoclimatic interpretations of possible glacial features, estimates of the volume of ice that may have been involved, and speculation regarding the ultimate fate of that nowmissing $\mathrm{H}_{2} \mathrm{O}$.

Many types of martian landforms have been attributed to glaciation. If these interpretations are correct, then some of these features imply either a former climate capable of surface melting (Kargel and Strom 1992) or bed conditions capable of melting (Howard 1981, Clifford 1987, Kargel et al. 1995). Circumpo- lar glacial ice sheets may have once extended to mid-latitudes around both poles (Baker et al. 1991, Kargel and Strom 1992, Kargel et al. 1995). In the northern plains, the geomorphic evidence for glaciation may be attributable to the freezing and eventual grounding of ice associated with an ancient ocean or transient lakes and seas produced by outflow channel-forming floods (Kargel et al. 1995, Clifford and Parker 1999).

The geologic evidence that the polar layered deposits have undergone significant glacial flow remains ambiguous. Assuming that the layered deposits are more than a few percent ice, some flow must occur. The broadscale domal shape of the polar cap can be explained either by glacial flow (Budd et al. 1986, Clifford 1987, Kargel 1998, Fisher 2000, Greve 2000, Larsen and Dahl-Jensen 2000) or by ablation (Ivanov and Muhleman 2000). Layers exposed in troughs appear, to a first approximation, to be nearly horizontal and undeformed. However, glacial deformation occurs primarily at the base of glaciers and by flow that is primarily parallel to the bed; therefore, appreciable shear of horizontal layers can occur without obvious layer distortion. MOC images suggest local waviness in some exposures (M. C. Malin, remarks presented at the First International Conference on Mars Polar Science and Exploration, 1998). These could be due to flow deformation, a wavy topography on the erosional scarp exposing the layers (e.g., yardang-like forms eroded by katabatic winds), or waviness in the original surface on which the layers were deposited (e.g., caused by the nonuniform erosion of the surface at high obliquity).

The presence of the polar troughs, and particularly their apparent penetration to the underlying basement near the periphery of the cap, indicates that glacial flow is of lesser importance than ablation in creating the details of polar cap topography. Local flow might still occur as a result of the trough topographic relief, and near the center of the cap, flow may occur in the ice beneath the troughs (Fisher 2000). However, the presence of apparently undeformed craters on the south polar layered deposits indicates that any recent glacial flow there has been minimal (Herkenhoff 2000).

In the longitude range of $300^{\circ}-360^{\circ} \mathrm{W}$, at the edge of the north polar layered deposits, faint ridges are found that parallel the base of the deposits' terminal scarp (Fig. 5, Howard et al. 1982). These ridges are present at distances up to $20 \mathrm{~km}$ from the present scarp base. The simplest explanation for these low ridges is that they mark former positions of the terminal scarp, which is now inferred to be undergoing ablational retreat. It is uncertain whether these ridges are terminal or recessional moraines that required glacial flow for emplacement, or are just accumulations of eolian debris that have formed episodically at the base of the retreating scarp.

Unfortunately, in the absence of field evidence, the interpretation of many purported glacial features is likely to remain ambiguous. One possible way to detect flow by remote observation would be via penetrating radar images of any potential deformation of the internal layers of the polar ice. Such an investigation is currently planned as part of the Mars Express mission 


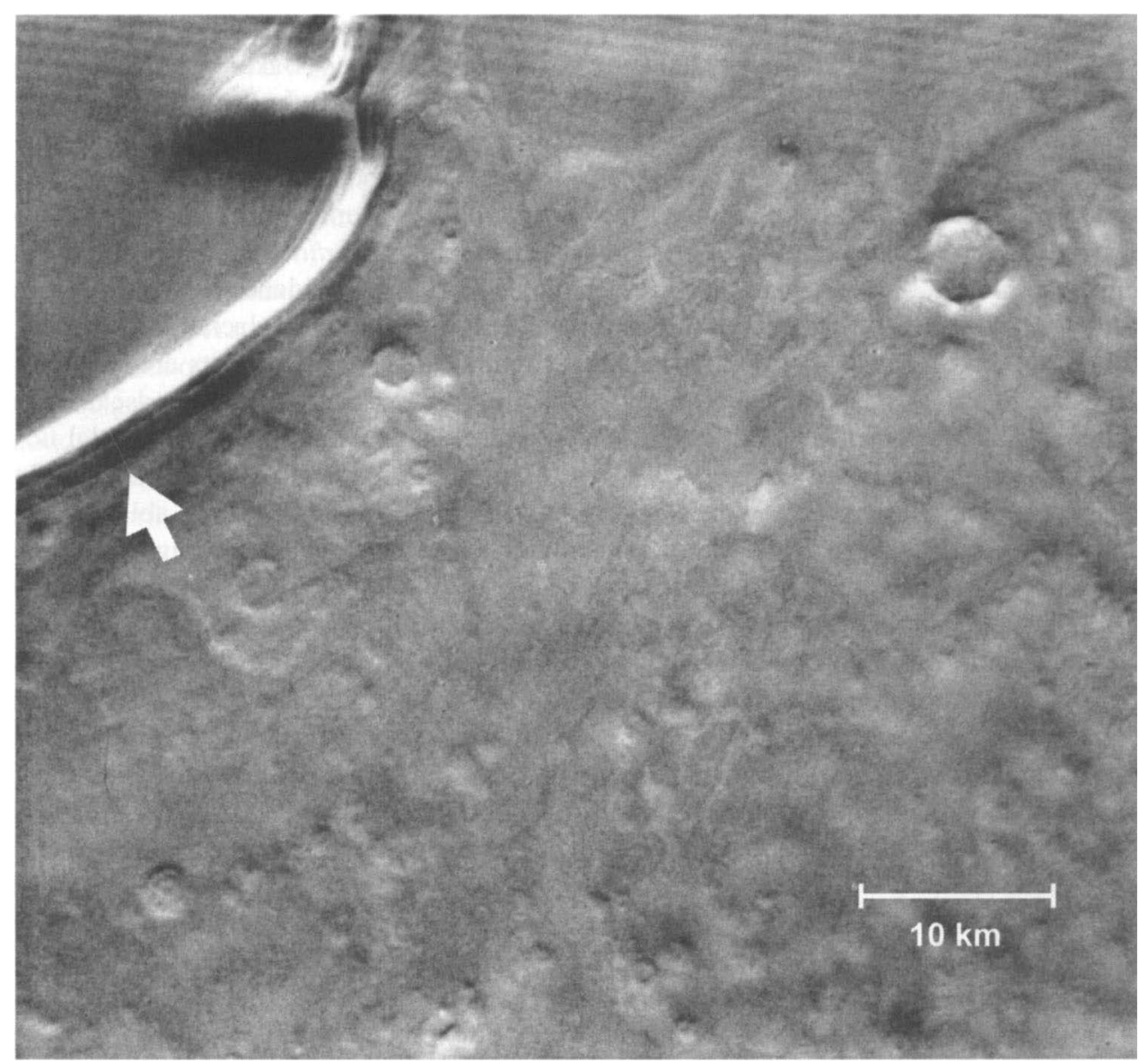

FIG. 5. Ridges that parallel the base of the equatorward-facing north polar terminal scarp (Viking Orbiter image 566B61). The ridges may simply be the erosional remnant of the former position of the scarp, debris that has accumulated at the scarp's base, or morraines formed by the flow or slip of the polar deposits at their base (Howard et al. 1982). The features in this image are located $\sim 10^{\circ}$ further clockwise along the periphery of the north polar deposits from the location of the Viking Orbiter frame highlighted in the inset to Fig. 2a.

in 2003. Other potential investigations are discussed by Clifford et al. (2000).

\subsection{The Prospects for Life}

Since 19th-century astronomers first reported telescopic observations of "canali" and albedo variations suggestive of the seasonal growth of vegetation, the search for life has been a primary driver of Mars research. Although the first reconnaissance of Mars by spacecraft during the 1960's failed to reveal any evidence of alien artifacts or desert oases, interest in the possibility of life was rekindled in 1971 with Mariner 9's surprising discovery of the valley networks and outflow channels. These features provide clear evidence of the considerable role that liquid water has played in the evolution of the martian surface.

Indeed, by the time the Viking Landers set down in 1976, interest in the possibility of indigenous life had grown to the point where much of the Landers' payload was dedicated to the search for organic material and evidence of metabolism. Although these experiments returned some unexpected results, no unambiguous evidence of life was found (Klein et al. 1992). The recent de- bate over potential evidence of life in the SNC meteorite ALH 84001 (McKay et al. 1996, Treiman 1999), combined with recent discoveries about the adaptability and diversity of life on Earth (Stevens and McKinley 1996, Onstott et al. 1998, Cowan 1999), has stimulated efforts to identify both better search strategies and more definitive indicators of past and present life. In this section we summarize several aspects of this work, with particular emphasis on the potential survival and preservation of life at the martian poles.

2.6.1. Environmental requirements and potential polar habitats. Although present surface conditions on Mars are hostile to life as we know it, there is substantial evidence that environmental conditions were considerably different in the past. The presence of the valley networks and the highly degraded state of the planet's most ancient terrains have been cited as evidence of an early warmer and wetter climate that may have persisted for as long as a billion years (Masursky et al. 1977, Pollack et al. 1987, Carr 1999). In addition, theoretical arguments, combined with the identification of a variety of geomorphic evidence, have led some to suggest that during this same period much of the 
planet's surface may have been covered by large standing bodies of water and ice (Clifford and Parker 1999). Whether the early climate was warm or cold, the presence of abundant water on the surface has profound implications for the development of life. Indeed, given the intense impact and volcanic activity that characterized the planet at this time, the development of longlived hydrothermal systems was likely widespread-duplicating many of the important conditions that are thought to have given rise to life on Earth (Farmer 1996).

If life did establish itself at this time, then its long-term survival was contingent on its ability to adapt to the subsequent changes in the planet's physical environment, particularly as it relates to the availability of liquid water (McKay et al. 1992). On Earth, access to liquid water is an essential condition for life. Its presence is required for the hydration of vital biomolecules such as DNA and proteins, for the function of lipoprotein membranes, and to support the dynamic ionic exchange required for metabolism (Horowitz 1979). However, on Mars, present conditions of temperature and pressure preclude the stable existence of liquid water at the surface (although the transient melting of ice may occur within the top centimeter of the equatorial regolith for several hours on the warmest days). Extremely low water activities at the surface of Mars present a formidable obstacle to life (Horowitz 1979, Klein 1992). In addition, because the thin $\mathrm{CO}_{2}$ atmosphere lacks oxygen, there is no ozone layer to protect the surface from ultraviolet radiation (Kuhn and Atreya 1979). Thus, the martian surface experiences a UV flux several times that normally regarded as lethal for terrestrial organisms.

For the above reasons, the search for extant life on Mars has focused on the identification of potential habitats where liquid water is continuously or episodically persistent, that provide protection from the Sun's UV, and where some energy source is available to support metabolism. Given the recent discovery of life in deep aquifers on Earth, one of the more promising possibilities for Mars is that, during the planet's early transition to a colder climate, life may have adapted to a subterranean existence where warmer temperatures and the potential presence of groundwater has enabled it to persist to the present day (Boston et al. 1992). The existence of a warm, subsurface aqueous environment is supported by the inferred age and origin of the martian outflow channels and by the mineralogical evidence of hydrous deposition and alteration within the 1.3-byr-old SNC meteorites (McSween and Harvey 1998, Warren 1998).

At the poles, the presence of groundwater at depth, particularly under the putative artesian conditions expected in the north (Clifford and Parker 1999), would satisfy all three of the environmental requirements for life identified above. The occurrence of liquid water at the surface is more problematic, but could transiently occur in response to local artesian discharges, basal melting due to local geothermal "hot spots" (or, earlier in the planet's history, due to the generally higher global heat flux), or to the melting of surface ice in response to the local enrichment of potent freezing-point depressing salts and/or the greater insolation experienced at high obliquity. With regard to the latter,
Pathare and Paige (1998) have demonstrated that as the obliquity increases beyond $35^{\circ}$, surface temperatures $>273 \mathrm{~K}$ can occur over progressively larger portions of the cap for extended periods during the spring and summer. On the other hand, the discharge of basal meltwater would tend to occur along glacial margins during episodes of rapid glacial retreat, or possibly as catastrophic discharges from more interior locations due to subglacial volcanic eruptions or intense geothermal heating. In either event, the flow of water to the surface could well entrain any existing organisms (or their byproducts) and deliver them into an environment where they would be captured and preserved as the discharges froze on the surface, creating deposits of ice.

The survival and persistence of liquid water environments at the martian poles is likely to be enhanced by the presence of dissolved salts. On Earth, groundwater that is in contact with crustal rocks for millions of years tends to evolve into a highly mineralized brine (Ingebritsen and Sanford 1998). Given the lack of rainfall and the isolation of martian groundwater beneath the surface for billions of years, its composition has undoubtedly experienced a similar geochemical evolution. Hypersaline conditions can depress the freezing point, thereby extending the envelope for liquid water and the lower end of the temperature range for the survival and growth of microbial life. In Antarctica, viable microbes are found in hypersaline lakes that remain unfrozen at temperatures as low as $245 \mathrm{~K}$ (Kerry et al. 1977). Don Juan Pond (Wright Dry Valley) is saturated with $\mathrm{CaCl}_{2}$ and freezes at $222 \mathrm{~K}$ (Marion 1997) but does not support viable bacteria at this temperature. In the Dry Valley soil profile, latent heat buffering and phase change effects in a mineral matrix result in liquid water detectable below $203 \mathrm{~K}$ (Anderson and Tice 1989). However, it is most unlikely that the membrane system of microbes, as we know them, could be functional at such low temperatures (Cowan 1999).

Terrestrial microbes have been shown to retain viability at subzero temperatures by exploiting thin films of brine on the surfaces of particles in permafrost soils (Gilichinsky et al. 1993). Microorganisms have been revived from Siberian permafrost estimated to be more than 3.0 Ma (Gilichinsky 1994, 1995; Zvyagintsev et al. 1985, 1990). However, the long term viability of microorganisms in ice has been questioned on a number of grounds, including the effects of prolonged background radiation which, in the absence of active DNA repair mechanisms, would rapidly destroy the genome (see Kennedy et al. 1994).

Hypersalinity reaches its limits in evaporite crusts such as salterns which support a rich diversity of viable microbes (Oren et al. 1995). Not only can cells metabolize in concentrated brine pockets, but the salt can also screen out dangerous UVB radiation (Clark 1998), promote longevity, and preserve residual biomolecules (Grant et al. 1998). Cyanobacteria (oxygenproducing photosynthetic bacteria) have demonstrated a remarkable capacity for shade-adaptation, with an ability to photosynthesize at very low irradiances. This capacity also enables cyanobacteria to avoid concomitant UVC and UVB damage 
by sheltering within mineral substrata such as salt crusts and iron-containing minerals (in lithosolic, sublithic, and endolithic habitats) (Clark 1998). They can also protect themselves by synthesizing pigments that act as sunscreens (Ehling-Schulz et al. 1997). This adaptation has allowed differently pigmented microbial layers to coexist in stratified communities (such as the stromatolitic mats and endolithic communities found in Antarctic Dry Valley streams, lakes, and sandstones) that take advantage of the cumulative screening provided by the successively deeper layers (Doran et al. 1998, Wynn-Williams 2000).

Mineral particulates appear to play an important role in promoting the survival and longevity of microbial populations in both permafrost and glacial ice (e.g., Christner et al. 2000). This is supported by the substantially larger microbial populations found in Antarctic soils (Vorobyova et al. 1997), compared to the more sparsely populated sediment-free ice-cores obtained from the Antarctic ice sheet itself (Abyzov 1993). This suggests that, on Mars, the presence of eolian dust in the polar layered deposits may be ecologically important, creating an environment similar to that of a terrestrial ice-cored moraine. Alternatively, in the near-surface, the dust may support the existence of hypersaline photosynthetic cryoconite communities, warmed by solar radiation. Analogous communities are found on Earth within the ice covers of McMurdo Dry Valley lakes (Priscu et al. 1998).

Certainly, the most abundant energy source at the surface of Mars is solar radiation; thus, if life evolved in surface environments, it probably adapted quickly to utilize this energy resource through some form of photosynthesis. As on Earth, the earliest photosynthesizers on Mars would likely have been anoxygenic forms, which could have given rise to later oxygenic forms similar to terrestrial cyanobacteria (Wynn-Williams 2000). The photolysis of water by terrestrial cyanobacteria gave them the freedom to occupy a broad range of habitats where liquid water was exposed to light under microaerophilic or locally (selfgenerated) aerobic conditions. Similar habitats may have existed at the martian surface early in the planet's history, when liquid water was more widespread.

Terrestrial chemolithotrophs (iron-reducing bacteria, sulfur bacteria, methanogens, and other Archaea) are limited to redox electron transfer in anaerobic habitats and exhibit metabolic flexibility, which allows them to occupy a broad range of subsurface habitats (Boston et al. 1992, Gold 1992). Chemolithoautotrophy (a metabolic strategy that is based on organosynthesis from simple inorganic substrates like $\mathrm{CO}_{2}$ and $\mathrm{H}_{2}$; see Stevens and McKinley 1996) is especially relevant for Mars in that it requires no organic input from surface systems. Subsurface ecosystems could exist in complete isolation from the martian surface (e.g., geothermal groundwaters; Nealson 1997) with little or no surface expression.

In the search for extant life at the poles, we will need access to subsurface environments where liquid water could exist. Because of the technological requirements for deep drilling, this is unlikely to occur before human missions. Thus, the principal objective of near-term robotic investigations in this effort will be the remote identification of potential surface or basal habitats. Sites of periodic water ice fogs, or spatially restricted anomalies in atmospheric volatiles (especially reduced gases like methane), could provide important clues for targeting future surface missions aimed at drilling into the shallow subsurface.

2.6.2. Exploring for fossil life on Mars. An alternative approach to the exobiological investigation of the poles is to identify and sample surface sedimentary deposits that are likely to have captured and preserved a record of fossil life or prebiotic chemistry from surface or subsurface communities (WynnWilliams 1999, Farmer 1999). In searching for evidence of an ancient martian biosphere (i.e., one that existed prior to $3.5 \mathrm{Ga}$ when surface conditions may have been more clement for life) it is important to understand the factors that promote the fossilization and long-term preservation of microbial biosignatures (Farmer and Des Marais 1999).

The most important factor in fossilization is the rapid entombment of organisms (and/or their byproducts) in a fine-grained, impermeable mineral matrix. This commonly occurs during the precipitation of primary aqueous minerals and secondary cements, during burial by clay-rich sediments, and by entrapment in crystallizing ice. The rapid isolation of organic materials from oxidizing fluids is crucial for preservation. One must also consider the chemical stability of the host mineralogy. The most stable common materials are silica, phosphate, and clays, as illustrated by the fact that most cellular fossils in Precambrian rocks on Earth are found in chert, phosphorite, and shale (e.g., Schopf 1993). The most favorable surface environments for microbial fossilization include arid lake basins, mineralizing surface springs, and hard pan soils. However, given the likely presence of groundwater on Mars throughout much of its history, subsurface mineralization has likely also been importantsamples of which may have been excavated and brought to the surface by impacts or through the disruption of the crust by catastrophic outflow events.

Perhaps the greatest concern for the long-term cryopreservation of biological materials at the poles is the potential for widespread melting at times of high obliquity (Pathar and Paige 1998). Such melting could well result in the loss of any accumulated inventory of organic or prebiotic chemical information. However, even if such episodes have occurred, there may still be high latitude sites on Mars where near-surface ground ice has been regularly replenished from the discharge of subsurface aquifers, thus providing accessible, cryospreserved samples of a subsurface environment where life might still exist.

\subsection{Key Questions and Needed Observations}

Since the first high-resolution images of the martian polar caps were returned by Mariner 9 in 1971, the central question that has driven Mars polar research has been: is there an interpretable record of climate and geologic history preserved in the polar deposits? Over the past 30 years, significant progress 
has been made in understanding the nature and evolution of the polar terrains. This is especially true of the recent discoveries and insights provided by the investigations of the Mars Global Surveyor spacecraft. However, despite these advances, many fundamental properties of the polar deposits are still unknown, and many critical issues remain unaddressed. To date, the most thorough review of key questions and needed observations regarding the polar regions is that compiled by the participants in the First International Conference on Mars Polar Science and Exploration (Clifford et al. 2000), which is summarized in Table I.

Although the extensive interrelationships that exist between questions about the origin and nature of the martian polar deposits complicates efforts at strict categorization, the four key questions identified in Table I effectively summarize the most fundamental uncertainties in our understanding of the poles, i.e., (I) What is the composition, structure, and chronology expressed in the stratigraphy of the polar deposits? (II) What is their mass and energy budget and what processes control them on seasonal and longer timescales? (III) What is their dynamical history? (IV) Are there environments within the polar regions where liquid water is (or was) present which could have provided habitats for life?

Because questions (I) and (II) are directly associated with measurable physical, thermal, and radiative properties, they are the ones most readily addressed by present and upcoming spacecraft missions. The most notable exception to such readily measurable properties is the determination of absolute age. Without an accurate chronology of the development of the polar stratigraphy, the potential for any significant advance in our understanding of the geologic and climatic record preserved at the poles is severely limited. While the problem of determining absolute ages has long appeared intractable, terrestrial researchers have recently identified at least one technique that offers promise in this application (Lepper and McKeever 2000), a topic that will be discussed in greater detail in Section 4.

TABLE I

Key Questions and Needed Observations ${ }^{a}$

The principal goal of Mars polar research is to determine whether there is an interpretable record of climatic and geologic history that has been preserved in the polar deposits.

I. What is the composition, structure and chronology expressed in the stratigraphy of the polar deposits?

A. Externally accessible/measurable properties.

1. Age of exposed layers as a function of stratigraphic position.

2. Thickness, extent, and continuity of layers.

3. Composition, structure, and ice- and dust-grain characteristics of layers.

4. Present surface strain rate.

B. Internal properties.

1. Basal topography.

2. Internal structure.

3. Geothermal heat flux.

4. Thermal conductivity and temperature profile.

5. Density and porosity.

6. Gas permeability.

II. What are the mass and energy budgets of the polar deposits, and what processes control them on seasonal and longer timescales?

A. Current radiation budget (incident, reflected, transmitted, and emitted), including the variation of radiation balance with season and the effects of dust and ice clouds in the atmosphere.

B. Current mass balance (mechanisms, rates, and spatial distribution) of $\mathrm{CO}_{2}, \mathrm{H}_{2} \mathrm{O}$, and dust.

C. Effects of high and low obliquity.

D. Cause of the north/south asymmetry in the seasonal evolution and physical characteristics of the polar deposits.

E. Processes and role of in situ modification (e.g., grain densification and geochemical alteration).

F. Evidence for or against a feedback between climate and polar insolation.

III. What is the dynamical history of the polar deposits?

A. Geomorphic or geophysical evidence of prior variations in vertical and areal extent.

B. Evidence of flow (either past or present) and its current role in controlling the shape of polar caps.

C. Origin of polar troughs and major reentrants.

$I V$. Are there places within the polar regions where liquid water is or was present and that may have provided habitats for past or present life?

A. Evidence of past or present basal melting or basal lakes.

B. Identification of peripheral ice deposits associated with local discharges of subpolar or subpermafrost groundwater.

C. Existence of microscale near-surface environments (e.g., endolithic, stromatolitic, or ice-rich permafrost) capable of sustaining life.

D. Evidence of episodic surface melting associated with high obliquity.

E. Presence of molecular biomarkers or microfossils in polar layered deposits.

${ }^{a}$ As identified by the participants in the First International Conference on Mars Polar Science and Exploration (Clifford et al. 2000). 


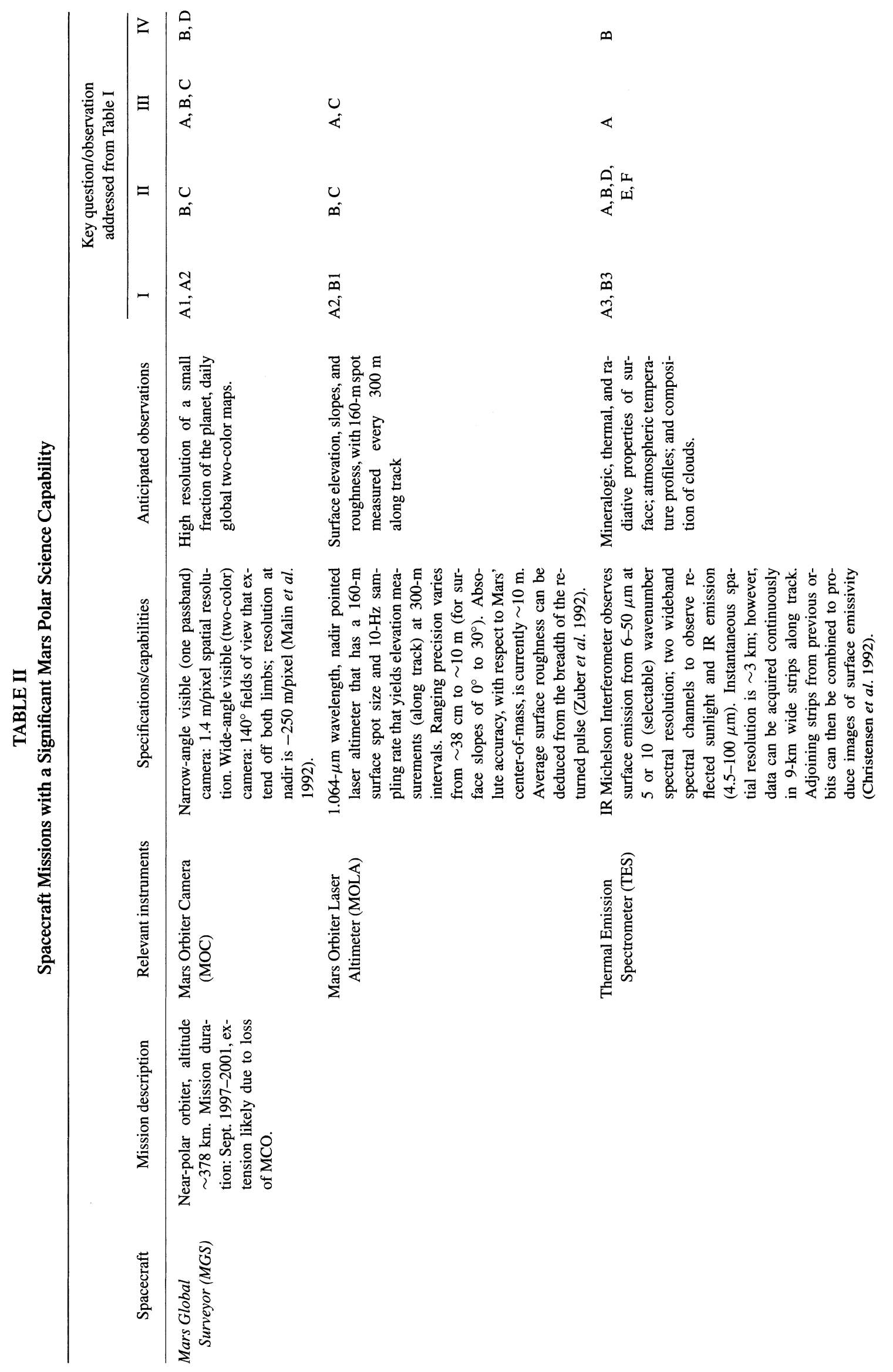




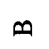

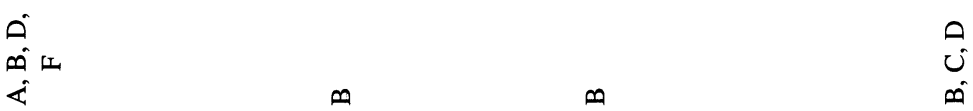

?

$\frac{2}{4}$

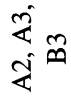

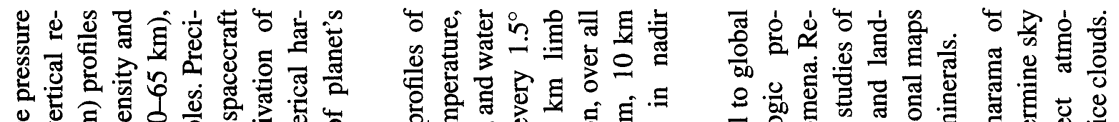

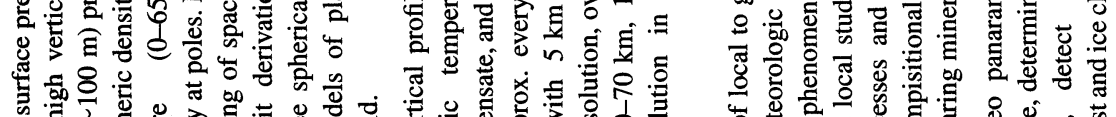

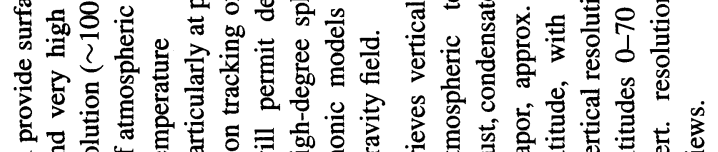

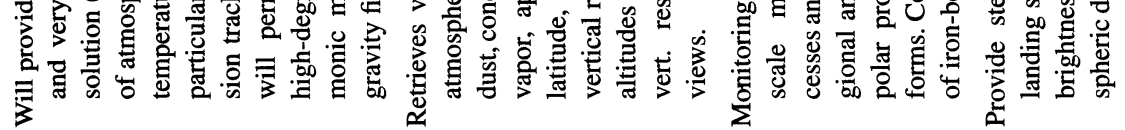
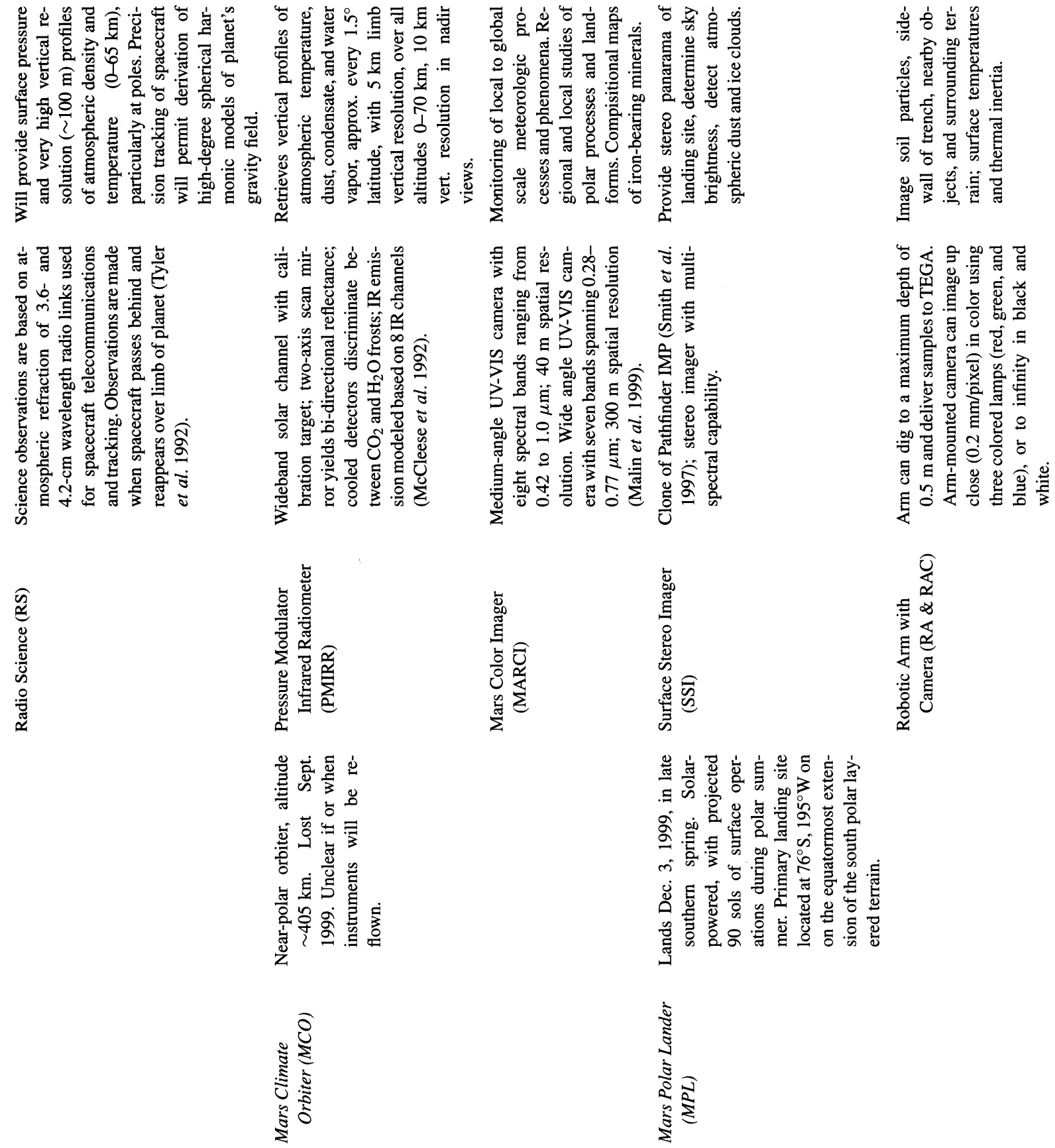

$\frac{\sqrt{2}}{5}$ 


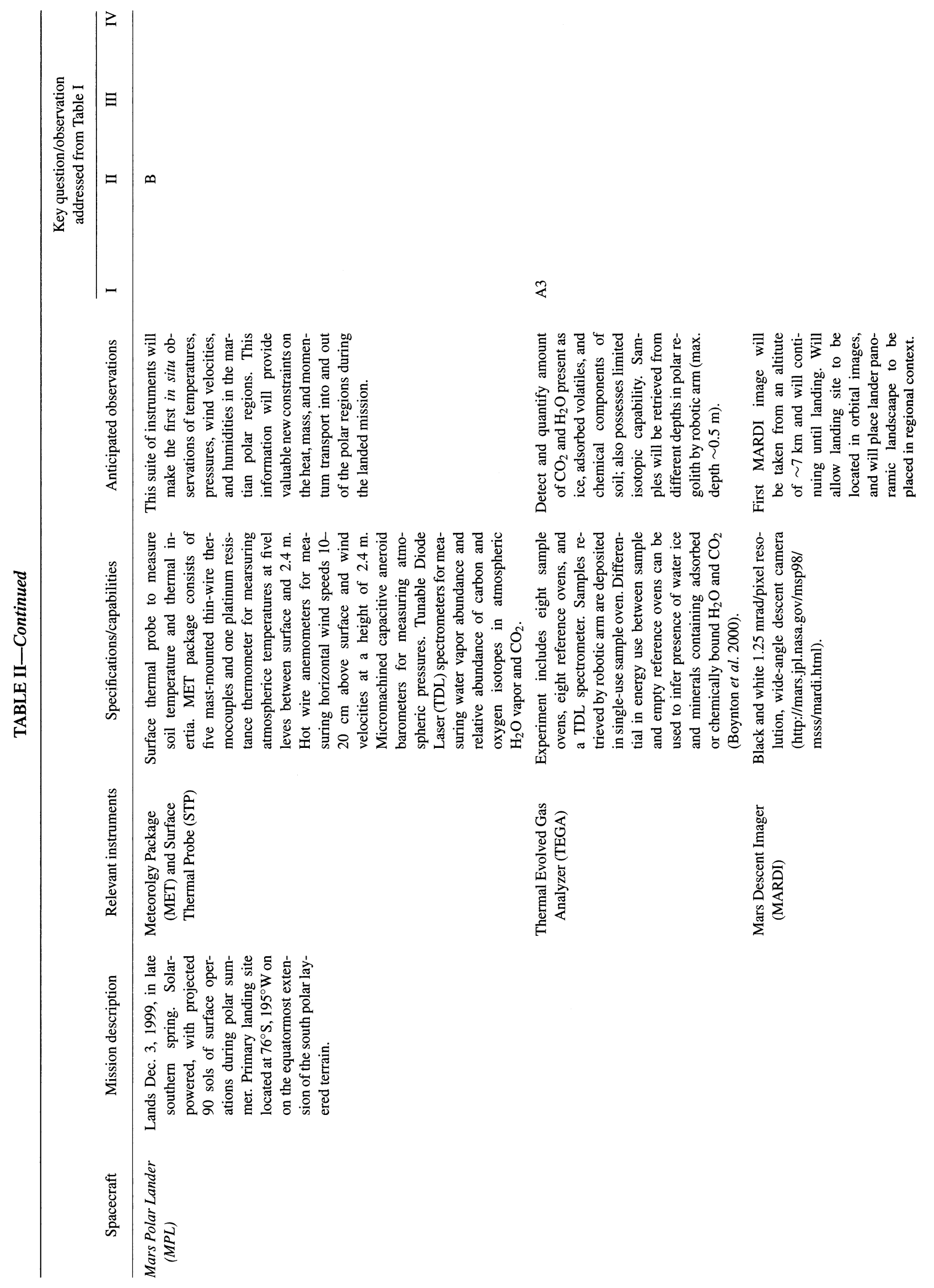




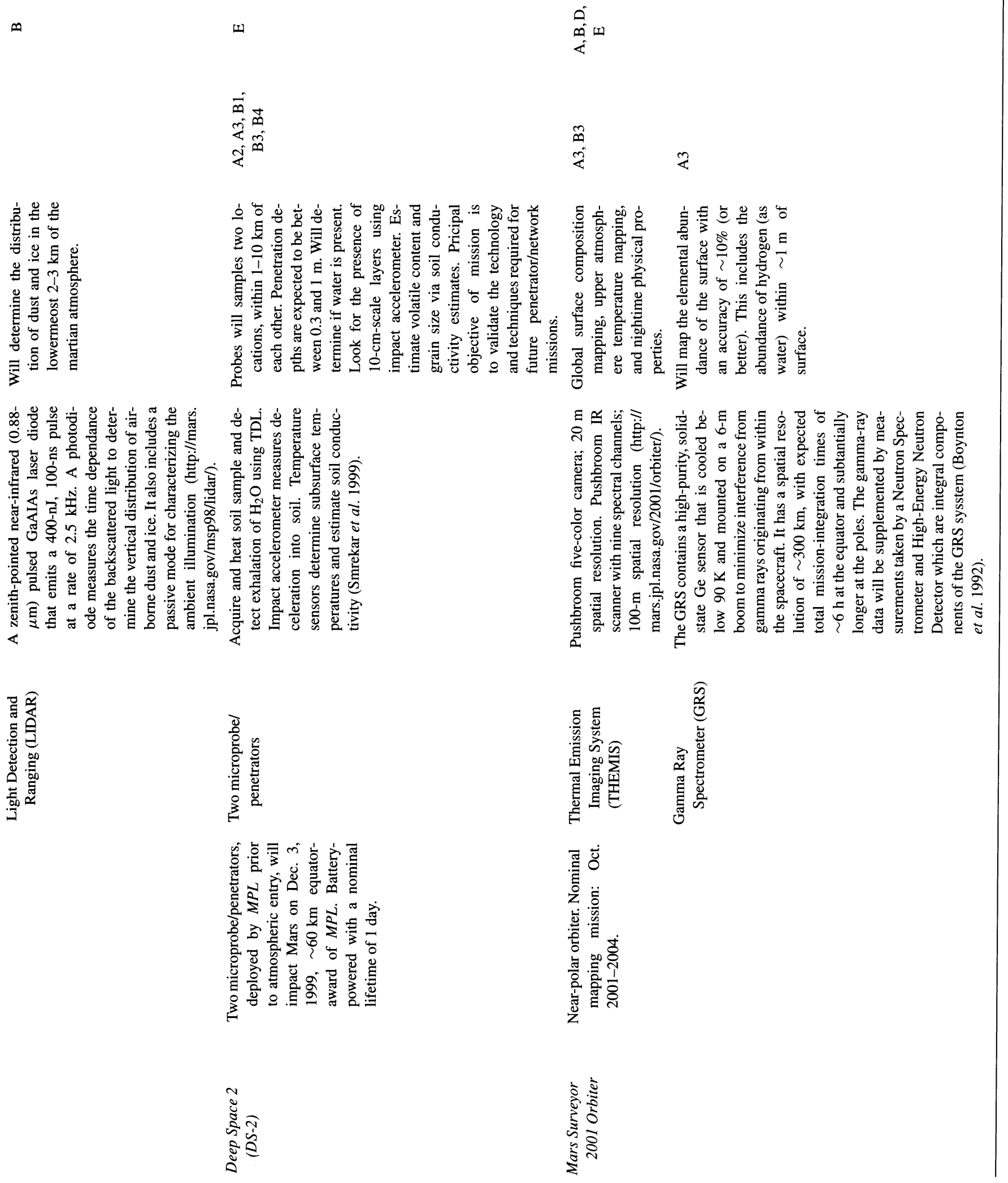




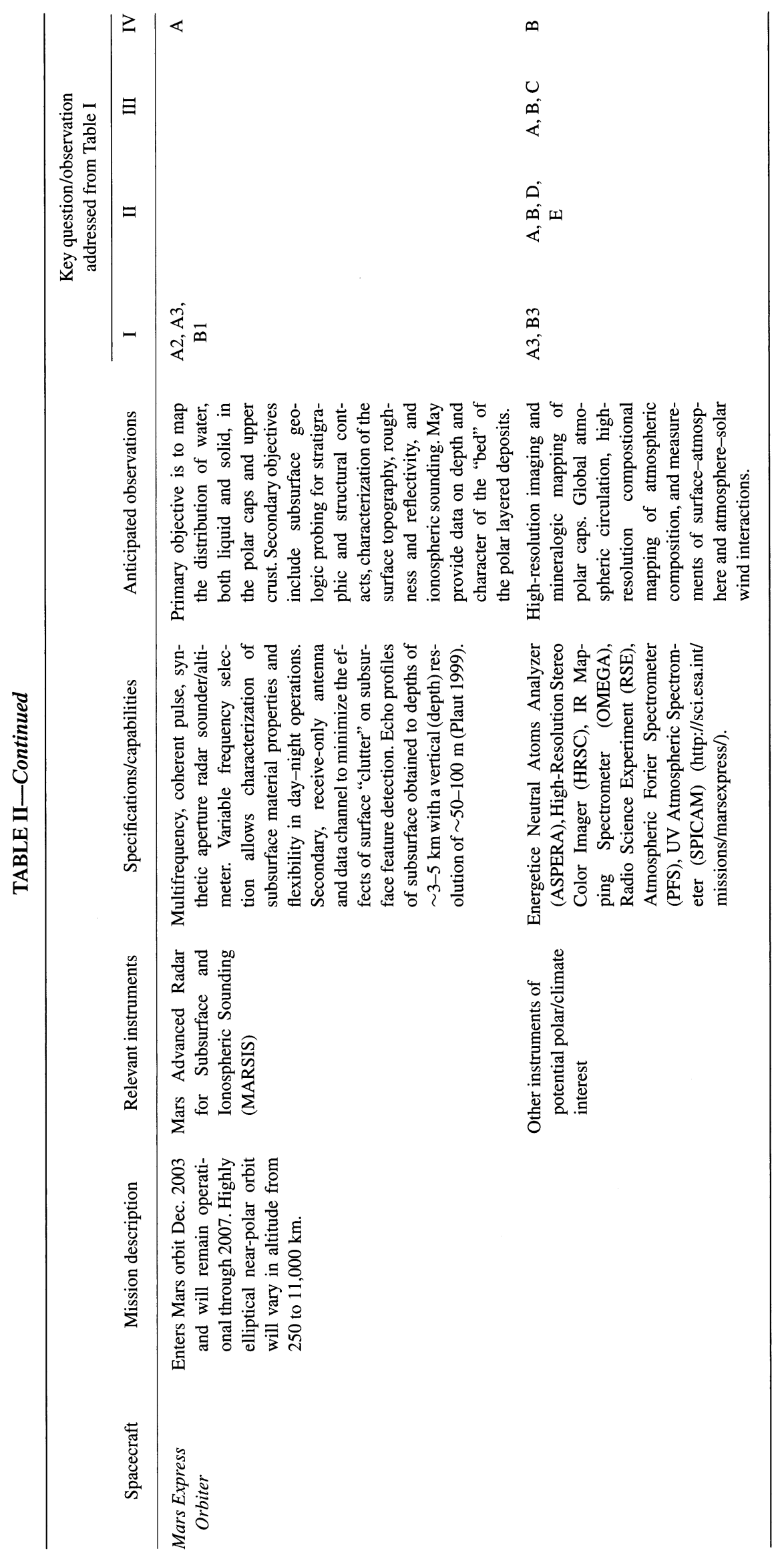


In the section that follows, we review the potential for current and future spacecraft missions to address the key questions and needed observations identified in Table I. We then follow that discussion with a brief assessment of the scientific issues that are likely to remain outstanding, and what scientific and technological challenges must be addressed before we can resolve them.

\section{MARS POLAR EXPLORATION: CURRENT AND FUTURE MISSIONS}

Since it entered Mars orbit in 1997, Mars Global Surveyor has returned a wealth of new information about the topography, geomorphology, and thermal characteristics of the planet's surface and atmosphere, making some of its most surprising and important findings at the poles. If all goes as planned, in December of 1999, MGS will be joined by two other spacecraft: the Mars Polar Lander (MPL) and the twin New Millennium Project's Deep Space-2 (DS-2) microprobes, which are the first spacecraft ever tasked with actually landing on a polar surface.

Between now and 2005, Mars will be visited by a number of other spacecraft that will include orbiters, landers, rovers, and at least two attempts at sample return. Although the primary objective of the orbiters is to conduct a general survey of the entire planet, their near-polar trajectories make them ideal platforms from which to conduct observations of the polar atmosphere and surface-an opportunity for which many of their instruments have been specifically targeted and optimized. Similarly, while the 2001 and later lander missions are directed at low latitudes, their investigations will provide valuable insights into the nature and history of the global environment, enabling more accurate interpretations of the geologic and climatic record preserved at the poles.

Table II lists the mission durations, relevant instruments, and anticipated polar observations of those spacecraft currently in operation, under construction, or in development that possess a significant capability for conducting Mars polar research. Aside from the direct investigations conducted by the $M P L$ and $D S-2$ spacecraft, perhaps the most anticipated mission for Mars polar science is the European Space Agency's (ESA's) Mars Express Orbiter that will be launched in 2003. Among that spacecraft's extensive complement of instruments is a radar sounder, whose electromagnetic investigations of the subsurface may provide a first look at the internal structure and basal topography of the polar layered deposits. These capabilities are discussed in greater detail below.

Observations by the fleet of spacecraft described above will dramatically impact our present understanding of the polar regions, providing many new insights regarding the physical characteristics, properties, and processes that have influenced their evolution. In this section we give a brief overview of these missions, the measurements they are expected to acquire, and the relevance of these observations to addressing the key questions and needed observations summarized in Table I. Additional in- formation, including late-breaking-news and links to the most recent data returned by these missions, is available through the Mars Surveyor Program and European Space Agency websites: http://mars.jpl.nasa.gov/ and http://sci.esa.int/marsexpress/.

\subsection{Mars Global Surveyor (Sept. 1997-2001)}

The MGS mission is the most ambitious and comprehensive orbital reconnaissance of Mars yet planned by NASA's Mars Surveyor Program. Its principal polar science objectives include characterization of the shape and volume of the residual ice caps and polar layered deposits (Zuber et al. 1998, Smith et al. 1999, Johnson et al. 2000); an investigation of the nature and stratigraphy of polar landforms at meter-scale resolution; quantification of the polar radiative balance (which controls the seasonal polar caps on short time scales and the existence and extent of the permanent ice caps on much longer time scales; Kieffer et al. 2000); and characterization of martian atmospheric transport and boundary conditions to provide better constraints on modeling the past and present climate.

These investigations are being carried out by four of the five instruments carried aboard $M G S$, which include the MOC, whose two wide-angle imagers have $140^{\circ}$ fields of view that extend off of both limbs and whose narrow-angle camera has a surface resolution of $1.5 \mathrm{~m} / \mathrm{pixel}$ (an order of magnitude improvement over the highest resolution images returned by the Viking Orbiters, Malin et al. 1992); the MOLA, which has a $160-\mathrm{m}$ spot size and a ranging precision that varies from $\sim 38$ $\mathrm{cm}$ up to $\sim 10 \mathrm{~m}$, depending on surface slope (Zuber et al. 1992); and the TES, which has a spectral range of 6-45 $\mu \mathrm{m}$, a spectral resolution of 5 or 10 wavenumbers, and a spatial resolution of $\sim 3 \mathrm{~km}$ (Christensen et al. 1992).

Although bandwidth limitations have restricted the number of meter-scale images returned by MOC (i.e., less than $1 \%$ of the planet's surface is expected to be imaged at this resolution by the mission's end), the polar orbit of $M G S$ has resulted in better spatial coverage of the poles than of any other equivalent area on the planet. In contrast to MOC, the substantially smaller data volumes generated by MOLA and TES have allowed almost continuous operation. This capability resulted in the release of the first high-resolution maps of polar and global topography within just a few months of the start of the primary mission (Smith et al. 1999). It has also allowed TES to acquire numerous 9-km wide strips of data along track that can be combined with adjoining strips (obtained during previous orbits), to produce images of the compositional, thermal, and radiative properties of the surface.

$M G S$ also includes two other investigations: a Radio Science (RS) experiment that uses the spacecraft's transmissions to Earth to improve our present knowledge of the martian gravity field, topography, and atmosphere, and a Magnetometer (MAG) to characterize the martian magnetic fields, ionospheric structure, and the interaction of Mars with the solar wind. All of the $M G S$ instruments are based on the designs of nearly identical instruments that were flown on the Mars Observer spacecraft, which 
was lost upon its arrival at Mars in 1993. These instruments are described in substantially more detail elsewhere (e.g., Chapman and Albee 1992; and Albee et al. 1998).

\subsection{Mars Climate Orbiter (Lost Sept. 1999)}

The loss of the Mars Climate Orbiter on September 23, 1999 was a major setback for both surface and atmospheric studies of the poles. The key polar science objective of $M C O$ was to develop an improved understanding of the thermal and physical processes controlling the present seasonal cycles of $\mathrm{H}_{2} \mathrm{O}, \mathrm{CO}_{2}$, and dust, particularly as it relates to the exchange of water vapor between the polar caps, atmosphere, and subsurface, and the fate of dust deposited on and eroded from the caps.

$M C O$ carried two instruments: the dual-camera Mars Color Imager (MARCI) and an atmospheric sounder, the Pressure Modulator IR Radiometer (PMIRR). MARCI's seven-colorfilter wide-angle camera (with a resolution similar to MOC's WA camera) and eight-filter medium-angle camera (with a 40-m resolution at nadir) was to provide information on the spatial distribution, character, and movement of atmospheric clouds and hazes at high latitudes, as well as extensive surface coverage of the polar regions during the hemispheric spring and summer (Malin et al. 1999). PMIRR (a copy of the atmospheric sounder previously lost with Mars Observer) was to observe the atmosphere above the planet's trailing limb, providing information on the vertical profiles of temperature, dust, condensate, and water vapor (McCleese et al. 1992). PMIRR was also designed to observe the growth and retreat of the seasonal polar caps, characterizing changes in the reflectivity and emissivity of the polar ice using a two-axis scan mirror that would have enabled measurements of reflected sunlight at a variety of emission and incidence angles (substantially extending the bidirectional reflectance coverage of TES). At the time this is written, it is not yet known whether MARCI or PMIRR will be recovered as part of a future mission.

\subsection{DS-2 Microprobes and Mars Polar Lander (Dec. 3, 1999, Duration: $D S-2 \sim 1$ day; $M P L \sim 90$ days)}

On December 3, 1999, the MPL and DS-2 spacecraft will arrive at Mars to conduct the first in situ investigations of the planet's south polar region. Shortly before atmospheric entry, the $M P L$ will release the twin $D S-2$ penetrator/microprobes that will impact the surface at a velocity of $\sim 200 \mathrm{~m} / \mathrm{s}$, embedding themselves as much as a meter beneath the surface of the polar deposits, and up to several kilometers apart. The microprobes will be followed by the $M P L$, a larger and more traditional lander that will use parachutes and retrorockets to set down about $60 \mathrm{~km}$ closer to the pole. The landing site, which is at $76^{\circ} \mathrm{S}, 195^{\circ} \mathrm{W}$, lies on a gently rolling plain located just inside the periphery of the south polar layered deposits and approximately $800 \mathrm{~km}$ away from the pole.

While reliance on battery power will limit the subsurface investigations of the $D S-2$ microprobes to just a single day, the solar-powered $M P L$ has an expected lifetime of $\sim 3$ months (although there is a small possibility that the spacecraft may survive the south polar winter in hibernation, to be revived the following spring). Over the duration of their respective missions, these spacecraft will conduct investigations to characterize the south polar surface environment, including its meteorology, geology, and especially the physical properties and behavior of volatiles in the seasonal evolution of the atmosphere and polar cap.

The DS-2 microprobes were developed to validate the technology and techniques required to build and deploy the nodal elements of future seismic and meteorology network missions (Smrekar et al. 1999). Although limited by both their small size and limited power, the $D S-2$ microprobes will conduct four science investigations. During the probes' descent, data obtained from two onboard accelerometers will be used to derive a profile of atmospheric density, as well as characterize the hardness, depth of penetration, and possible presence of layering (on the tens of centimeters scale) within the near-surface polar deposits. Upon impact, the penetrators will separate into two parts: an aftbody that remains at the surface and communicates with the $M G S$, and a forebody that plunges to a depth of up to $1 \mathrm{~m}$. Once the forebody comes to rest, a drill will extract a small sample of deposit material, heat it above $0^{\circ} \mathrm{C}$, and look for the presence of water vapor using a tunable diode laser. Two temperature sensors in the forebody will also monitor the rate at which the probe cools. The thermal conductivity of the deposits will then be estimated by comparing the observed cooling rate on Mars with previously calibrated models of probe cooldown.

As noted above, a principal science objective of the Mars Polar Lander is the characterization of the local geology. This investigation will actually begin after the aeroshell falls away as the MPL descends to the surface. Throughout that descent the Mars Descent Imager (MARDI) will take a series of images to provide the regional context necessary to both interpret the landscape viewed from the surface and to aid in the identification of the landing site's exact location in orbital imagery.

Once on the surface, the $M P L$ will immediately begin to pursue its other science objectives, which include observations of the quantity and behavior of subsurface, surface, and atmospheric $\mathrm{H}_{2} \mathrm{O}$; determination of the isotopic abundance of $\mathrm{H}_{2} \mathrm{O}$ and $\mathrm{CO}_{2}$ in the atmosphere and subsurface; the search for fine-scale layering within the near surface deposits; and determination of the abundances of volatile minerals, such as hydrates and carbonates, that may have formed in ancient martian seas and have since been blown into the polar regions as part of the dust raised by local and global dust storms.

Assisting in these investigations is a payload that consists of a laser sounder (LIDAR) system for ranging atmospheric hazes and an integrated instrument suite called MVACS (Mars Volatiles and Climate Surveyor). MVACS includes a Surface Stereo Imager (SSI) that will take panoramas of the landing site in 12 spectral channels and in stereo and will be used to both study the local geology and derive atmospheric levels of dust and water, as well as detection of clouds and hazes. The 
Meteorological Package (MET) will measure atmospheric winds, pressure, temperature, and humidity near the surface. A robotic arm (and arm-mounted camera) will be used to investigate the surface, trench into it (Kossacki et al. 2000), image the sidewalls of the trench (with a resolution sufficient to resolve mineral grains or annual layers as small as a few tens of micrometers in size), and acquire samples for analysis by the Thermal Evolved Gas Analyzer (TEGA). The TEGA will heat soil samples provided by the robotic arm to detect the presence of carbon dioxide and water as ices, absorbed phases, and chemically bound in the mineral component of the local polar deposits.

\subsection{Mars Surveyor 2001 Orbiter and Lander} (Oct. 2001-July 2004)

Another orbiter and lander pair will be sent to Mars during the 2001 launch opportunity. The orbiter will include two instruments: the Thermal Emission Imaging System (THEMIS) and Gamma Ray Spectrometer (GRS). The THEMIS instrument will image the polar surface both visually and in several thermal infrared wavelength bands, with a corresponding spatial resolution of 20 and $40 \mathrm{~m}$. This will provide a significant improvement in detail over the compositional, thermal, and radiative investigations conducted by TES. Meanwhile, the GRS (which will also include a Neutron Spectrometer and possibly a High Energy Neutron Detector) will carry out an elemental survey of the planet's near-surface (top $0.5 \mathrm{~m}$ or so), mapping the distribution of hydrogen as a means of locating near-surface water (Boynton et al. 1992).

Although targeted for an equatorial location, the 2001 Lander includes two instrument suites that will provide the first comprehensive characterization of the dust that is raised by local and global dust storms and ultimately deposited and entrained in the polar ice. The Athena Precursor Experiment (APEX) will provide information on the thermal properties, chemical composition, and iron mineralogy of the dust (Squyres et al. 1999), while the Mars Environmental Compatibility Assessment (MECA) payload will provide data on dust particle size, morphology, composition, and electrostatic properties (Marshall et al. 1999). Together, this information will provide valuable insights about the optical properties of the dust suspended in the atmosphere, its potential effectiveness as condensation nuclei for $\mathrm{H}_{2} \mathrm{O}$ and $\mathrm{CO}_{2}$, the concentration and composition of soluble salts it may introduce into the polar ice, its effect on the rheologic, thermal, and optical properties of the ice, and the potential complications it may pose for future geophysical and deep drilling investigations of the polar layered deposits.

\subsection{Mars Express Orbiter (Nominal Mission, Dec. 2003-2006)}

The European Space Agency (ESA) is currently planning to launch both an orbiter and lander to Mars in 2003. Although the lander (Beagle 2) will pursue investigations unrelated to the poles, the Mars Express Orbiter payload contains a broad array of sophisticated instruments (Table II; http://sci.esa.int/missions/ marsexpress/) that will provide one of the most comprehensive surveys of Mars (and the polar regions) yet attempted. While several of these instruments will provide important new observations of the polar atmosphere and surface, perhaps the most eagerly anticipated are the electromagnetic investigations that will be conducted by the Mars Advanced Radar for Subsurface and Ionospheric Sounding (MARSIS).

MARSIS is a multifrequency, coherent pulse, synthetic aperture radar sounder/altimeter that will investigate the internal structure (and potentially detect the basal topography) of the polar layered deposits (Plaut 1999). The variable frequency capability permits a fuller characterization of subsurface material properties and increases the flexibility of the instrument in daynight operations. The sounder will acquire echo profiles of the subsurface at a lateral spacing of approximately $5 \mathrm{~km}$ and a vertical (depth) resolution of 50-100-m.

The primary objective of the MARSIS experiment is to map the distribution of water, both liquid and solid, in the upper portions of the martian crust. Secondary objectives include subsurface geologic probing for stratigraphic and structural contacts, characterization of the surface topography, roughness and reflectivity, and ionospheric sounding.

Data from MARSIS could potentially address several critical issues in Mars polar research (Plaut 1999). For example, discontinuities in dielectric properties within the layered deposits may provide evidence of major shifts in climate, periods of intense volcanic activity, or internal deformation associated with glacial flow. The properties of other high-latitude terrains will also be studied, including the thickness of the north polar erg, and possible subsurface stratigraphic contacts among sedimentary, volcanic, and ice deposits. But perhaps of greatest interest is the potential for investigating the depth and character of the polar layered deposits' "bed." If attenuation of the signal by the layered materials is not too great, it may be possible to map the base of the deposit and detect basal melting zones, should they exist. The detection of either shallow $(<5 \mathrm{~km})$ aquifers or "pockets" of basal meltwater beneath the polar ice would be a dramatic result, with potential implications for local ecosystems, as well as the planet's regional, and possibly global, hydrology. Such a discovery would revolutionize our ideas on the current state of water on Mars and provide highpriority targets for follow-up exobiologic investigations of the poles.

\section{OUTSTANDING ISSUES AND NEEDED CAPABILITIES}

By the conclusion of the Mars Express mission, all currently planned investigations of the martian polar regions, conducted from orbit or the surface, will be complete. Although NASA, in cooperation with the European Space Agency, plans to send orbiter and lander pairs to Mars during the 2003 and 2005 launch opportunities, the lander component of these missions will be 
dedicated to the acquisition and return of surface samples from sites at low latitudes, while the goals and instrument suites (if any) of the orbiters are currently undefined. Because of the long lead times required for mission planning, and because the polar regions will remain a high priority objective of future Mars exploration and research, it is an appropriate time to assess what we expect to learn from current missions and what key issues are likely to remain outstanding.

Consideration of the instrument capabilities discussed in the previous section (and listed in Table II) suggests that significant progress will be made in characterizing the surficial compositional, thermophysical, and radiative properties of the polar deposits. In addition, perhaps as much as $10 \%$ of the polar regions will have been imaged at meter-scale resolution, with essentially complete coverage (in many colors) at a minimum resolution of several tens of meters. These images will provide unprecedented views of surface morphology and stratigraphy, and will yield important clues as to the nature, origin, and evolution of the polar terrains. Data from MOLA and MARSIS should provide an improved estimate of the thickness and volume of the polar deposits and, to a lesser degree, of the amount of water that may be stored as ice within them. On a larger scale, the synthesis of data obtained from a variety of instruments will yield global maps of the distribution and temporal variation of atmospheric water vapor, dust, clouds, and surface frosts, while other instruments may provide low-resolution maps of the distribution of subsurface $\mathrm{H}_{2} \mathrm{O}$ (as regolith adsorbate, near-surface ground ice, and perhaps even groundwater) to depths of up to several kilometers. When combined with wind directions and speeds derived from cloud track observations, this information should give us a much improved understanding of atmospheric transport and how water is exchanged between the regolith, atmosphere, and polar caps.

Yet, despite these many advances, in a very literal sense we will have only just begun to scratch the surface in our exploration and understanding of the martian polar regions. For example, while we will have amassed a large volume of data on the external properties of the polar deposits, their internal properties (such as gaseous permeability, porosity, density, rheology, thermal conductivity, temperature profile, and geothermal heat flux) will continue to remain a mystery. That ignorance may well extend to even more fundamental properties, such as the deposits' internal structure and basal topography. Indeed, although the radar sounding experiment on Mars Express is an important first step, the inherent difficulty of discriminating between the dielectric properties of ice, embedded dust, and a polar basement of unknown lithology introduces sufficient uncertainty in the interpretation of the radar data that a combination of other geophysical techniques and/or in situ drilling may be required for its validation.

Likewise, our ability to understand the influence of past climates on atmospheric circulation, the seasonal cycles of $\mathrm{CO}_{2}$, $\mathrm{H}_{2} \mathrm{O}$, and dust, and the polar mass balance will remain constrained by the lack of data necessary to fully and accurately characterize the present martian climate. On Earth, such studies are aided by a dense global network of surface, airborne, and orbital sensors that provide both ground truth and a high-resolution spatial and temporal record of the changes that occur in surface boundary conditions, fluxes, physical properties, and dynamics of the atmosphere. Although the investigations conducted by Mars spacecraft over the next several years will measurably advance our knowledge of the present climate system, to achieve any further progress will require a substantial increase in the resolution, frequency, geographic distribution, and duration of local and global monitoring.

The single greatest obstacle to unlocking and interpreting the geologic and climatic record preserved at the poles is the need for absolute dating (i.e., I.A.1 in Table I; see also Cutts and Lewis 1982, Thomas et al. 1992, Clifford et al. 2000). Until recently, the most promising method for establishing an accurate chronology of the polar stratigraphy appeared to be isotopic dating techniques based on the identification of horizons containing either ${ }^{10} \mathrm{Be}$ (with recent peaks produced by local supernova events 35 and $60 \mathrm{ka} \mathrm{BP}$; Beer et al. 1992) or volcanic ash (to which standard argon-dating techniques could then be applied; Dicken 1995). Either approach requires analytical capabilities and resources that greatly exceed those that might conceivably be employed in situ by robotic spacecraft, necessitating the remote acquisition, preservation, and return of drill core samples (tens to hundreds of meters in length) back to Earth for analysis. The magnitude of the cost and logistical problems associated with such an effort make it impractical to pursue. However, another approach, called luminescence dating, has recently been proposed that appears to have some promise in its potential application to Mars (Lepper and McKeever 1998, 2000). The technique is based on the fact that, in the absence of heat and sunlight, natural ionizing radiation will free electrons in the crystal lattice of mineral sediments that become trapped in defects. Heating or exposure to light then releases the trapped electrons, producing an amount of light that is proportional to the sediment burial time. This technique has been used to date terrestrial sediments ranging in age from 1 to $150 \mathrm{ka} \mathrm{BP}$, with a single measurement error of $\sim 15 \%$. Depending on the intensity of the natural radiation background on Mars, this maximum age limit could potentially be extended even further. A major asset of luminescence dating is that the required hardware is small enough that it can fit within the mass and volume constraints of a $D S$-2-sized penetrator. Whether this particular technique will ultimately prove viable for use in Mars exploration remains unclear, but the ability to sample and date in situ is a necessary prerequisite for deconvolving the complex stratigraphic record preserved at the poles.

Finally, while high-resolution images, radar sounding, and other forms of orbital reconnaissance are of obvious utility in the remote investigation of landforms or in mapping the distribution of various physical properties, there are other tasks for which they are ill-suited. For example, while a suspect glacial moraine or jökulhlaup deposit may be identified from orbit, such 
an identification will remain ambiguous without corroborating evidence obtained in the field. There is no better example of the need for in situ investigations than the search for evidence of past or present life. Clearly, the identification of microfossils or active endolithic communities is not a task that can be conducted from orbit, nor can it be pursued by a traditional lander, investigating a single site, with any reasonable chance of success. Even when the targeted environment is highly localized, practical considerations of landing precision and the density and visibility of potential finds are likely to require long-duration surface investigations conducted by robotic spacecraft that possess significant mobility, sample retrieval, and analytical capabilities. Alternatively, where the density or spatial coverage of potential finds is greater, the deployment of a large number of less capable (and less expensive) spacecraft might satisfy the need. While the development of such spacecraft may prove challenging, it is difficult to conceive of an exploration strategy that could successfully address the search for life, or any field investigation of similar complexity, without these capabilities. Depending on the specific polar science objective, there are a wide variety of exploration platforms and technologies that might be employed in such investigations - the greatest technical constraints on which are mass, mobility, communications, and power. These issues are discussed in greater detail by Clifford et al. (2000).

While there are presently no plans for a return to the polar regions following the $M P L$ and $D S-2$ missions, opportunities for more ambitious in situ investigations of the poles will almost certainly arise in the second half of this decade. These missions will benefit from the wealth of data returned by $M P L$ and $D S-2$, as well as a number of orbiter-based investigations. They will also benefit from a variety of innovative technologies, now in development, that will significantly enhance our ability to conduct extended investigations of the martian polar environment. From a scientific perspective, this second phase of polar exploration will mark the transition from the broad characterization of the physical and thermal environment to the development of comprehensive strategies to investigate the specific processes by which the polar deposits have evolved.

\section{SUMMARY}

By analogy with the major ice sheets of Earth, the martian polar deposits are believed to preserve a record of geologic and climatic history that extends back at least $\sim 10^{5}-10^{8}$ years. Their layered stratigraphy is thought to document variations in insolation (due to quasiperiodic oscillations in the planet's obliquity and orbital elements), volatile mass balance, atmospheric composition, dust storm activity, volcanic eruptions, large impacts (Lorenz 2000), catastrophic floods, solar luminosity, supernovae, and perhaps even the abundance of microbial life.

Because this potential storehouse of knowledge is unequaled anywhere else on the planet, the martian polar regions are likely to remain a high priority objective of current and future exploration. But to successfully access and interpret this record will require the development of spacecraft and instruments capable of monitoring and sampling the polar environment at multiple locations for extended periods of time, assessing its internal properties, and, most importantly, dating its stratigraphy through the ready application of in situ techniques.

Through such investigations, Mars polar science and exploration seeks to address four fundamental questions: What is the composition, structure and chronology expressed in the stratigraphy of the polar deposits? What is their mass and energy budget, and what processes control them on seasonal and longer timescales? What is their dynamical history? And, finally, are there places within the polar regions where liquid water is or was present that may have provided habitats for past or present life?

Over the next several years, ongoing investigations by Mars Global Surveyor, and a fleet of other spacecraft, will address many key elements of these questions and, in doing so, vastly enhance our understanding of the nature and evolution of the poles. This knowledge will lay the foundation for the more ambitious investigations that are likely to follow in the second half of this decade. Ultimately, the efforts of these robotic spacecraft will be supplemented by the arrival of humans-brought to the poles because of both the promise they hold for understanding the evolution of the planet and because of the valuable reservoir of accessible water they will provide to support the long-term exploration of Mars. In this way, the martian polar regions represent not only the key to the planet's past, but also its future.

\section{ACKNOWLEDGMENTS}

This summary benefited from the input of the more than one-hundred terrestrial and planetary scientists who participated in the First International Conference on Mars Polar Science and Exploration, which was held at Camp Allen, Texas, October 18-22, 1998. It also benefited from a helpful review and edit by James Bell. Work performed at the Jet Propulsion Laboratory, California Institute of Technology, was carried out under contract with the National Aeronautics and Space Administration. This is Lunar and-Planetary Institute Contribution 987.

Note added in proof. Mars polar science was dealt yet another major setback with the loss of the Mars Polar Lander (MPL) and Deep Space-2 (DS-2) missions in December. Although the Mars Global Surveyor spacecraft continues to return a wealth of new data about the nature and seasonal evolution of the poles, its recent discoveries have reemphasized the importance of addressing the science questions that originally motivated the $M P L$ and $D S-2$ missions. It is hoped that this lost opportunity will be recovered in an ambitious return to the poles within the next decade.

\section{REFERENCES}

Abyzov, S. S. 1993. Microorganisms in the Antarctic ice. In Antarctic Microbiology (E. I. Friedmann, Ed.), pp. 265-295. Wiley-Liss, New York.

Albee, A. L., F. D. Palluconi, and R. E. Arvidson 1998. Mars Global Surveyor Mission: Overview and status. Science 279, 1671-1672.

Allen, C. C. 1979. Volcano-ice interactions on Mars. J. Geophys. Res. 84, 80488059.

Anderson, D. M., and A. R. Tice 1989. Unfrozen water contents of six Antarctic soil materials. In Cold Regions Engineering Proceedings: Fifth International Conference of the American Society of Civil Engineers, pp. 353-366. American Scociety of Civil Engineers, New York. 
Anguita, F., R. Babín, G. Benito, D. Gómez, A. Collado, and J. W. Rice 2000. Chasma Australe, Mars: Structural framework for a catastrophic outflow origin. Icarus 144, 302-312.

Arthern, R. J., D. P. Winebrenner, and E. D. Waddington 2000. Densification of water ice deposits on the residual north polar cap of Mars. Icarus 144, $367-381$.

Arvidson, R. E., E. A. Guinness, H. J. Moore, J. Tillman, and S. D. Wall 1983. Three Mars years: Viking Lander 1 imaging observations. Science 22, 463468.

Baker, V. R. 1982. The Channels of Mars. Univ. of Texas Press, Austin.

Baker, V. R., M. H. Carr, V. C. Gulick, C. R. Williams, and M. S. Marley 1992. Channels and valley networks. In Mars (H. H. Kieffer, B. M. Jakosky, C. W. Snyder, and M. S. Matthews, Eds.), pp. 493-522. Univ. of Arizona Press, Tucson.

Baker, V. R., R. G. Strom, V. C. Gulick, J. S. Kargel, G. Komatsu, and V. S. Kale 1991. Ancient oceans, ice sheets, and the hydrological cycle on Mars. Nature 352, 589-594.

Barnes, J. R., R. M. Haberle, J. B. Pollack, H. Lee, and J. Schaeffer 1996. Mars atmospheric dynamics as simulated by the NASA/Ames general circulation model. 3. Winter quasi-stationary eddies. J. Geophys. Res. 101, 12,753$12,776$.

Barnes, J. R., J. B. Pollack, R. M. Haberle, R. W. Zurek, C. B. Leovy, H. Lee, and J. Schaeffer 1993. Mars atmospheric dynamics as simulated by the NASA/Ames general circulation model. 2. Transient baroclinic eddies. J. Geophys. Res. 98, 3125-3148.

Battistini, R. 1987. Indices morphologiques d'anciens glaciers dans les des basses latitudes de Mars: Leur relation avec l'hydrolithosphère. Inter-nord 18, 399-411.

Beer, J., S. J. Johnsen, G. Bonani., R. C. Finkel, C. C. Langway, H. Oeschger, B. Stauffer. M. Suter, and W. Wolfi 1992. ${ }^{10}$ Be peaks as time markers in polar ice cores. In The Last Deglaciation: Absolute and Radiocarbon Chronologies (E. Bard and W. S. Broecker, Eds.), pp. 141-153. Springer-Verlag, New York.

Bell, J. F., W. M. Calvin, M. E. Ockert-Bell, D. Crisp, J. B. Pollack, and J. Spencer 1996. Detection and monitoring of $\mathrm{H}_{2} \mathrm{O}$ and $\mathrm{CO}_{2}$ ice clouds on Mars. J. Geophys. Res. 101, 9227-9237.

Benito, G., F. Mediavilla, M. Fernandez, A. Morquez, J. Martinez, and F. Anguita 1997. Chasma Boreale, Mars: A sapping and outflow channel with a tectonothermal origin. Icarus 129, 528-538.

Bills, B. G. 1999. Obliquity-oblateness feedback on Mars. J. Geophys. Res. 104, 30,773-30,797.

Björnsson, H. 1974. Explanation of jökulhlaups from Grimsvötn, Vatnajökull, Iceland. Jökull 24, 1-26.

Blasius, K. R., J. A. Cutts, and A. D. Howard 1982. Topography and stratigraphy of martian polar layered deposits. Icarus 50, 140-160.

Boston, P. J., M. V. Ivanov, and C. P. McKay 1992. On the possibility of chemosynethetic ecosystems in subsurface habitats on Mars. Icarus 95, 300308.

Boynton, W. V., J. I. Trombka, W. C. Feldman, J. R. Arnold, P. A. J. Englert, A. E. Metzger, R. C. Reedy, S. W. Squyres, H. Wanke, S. H. Bailey, J. Bruckner, J. L. Calla, D. M. Drake, P. Duke, L. G. Evans, E. L. Haines, F. C. McCloskey, H. Mills, C. Shinidhara, and R. Starr 1992. Science application of the Mars Observer Gamma Ray Spectrometer. J. Geophys. Res. 97, 7681-7698.

Boynton, W. V., S. H. Bailey, D. K. Hamara, M. S. Williams, R. C. Bode, M. R. Fitzgibbon, W. J. Ko, M. G. Ward, K. R. Sridhar, J. A. Blanchard, R. D. Lorenz, R. D. May, D. A. Paige, A. V. Pathare, D. A. Kring, L. A. Leshin, D. W. Ming, A. P. Zent, D. C. Golden, H. V. Lauer, Jr., and R. C. Quinn 2000. The thermal and evolved-gas analyzer: Part of the Mars volatile and climate surveyor integrated payload. J. Geophys. Res., in press.
Budd, W. F., D. Jenssen, J. H. I. Leach, I. N. Smith, and U. Radok 1986. The north polar ice cap of Mars as a steady-state system. Polarforschung 56, 46-63.

Butler, B. J. 1994. The Radar Reflectivity of the Surfaces of Mars and Mercury: Planetological Implications, Ph.D. thesis. California Institute of Technology, Pasadena, CA.

Carr, M. H. 1979. Formation of martian flood features by release of water from confined aquifers. J. Geophys. Res. 84, 2995-3007.

Carr, M. H. 1986. Mars: A water-rich planet? Icarus 56, 187-216.

Carr, M. H. 1987. Water on Mars. Nature 326, 30-35.

Carr, M. H. 1999. Retention of an atmosphere on early Mars. J. Geophys. Res. 104, 21,897-21,909.

Carr, M. H., and J. G. Schaber 1977. Martian permafrost features. J. Geophys. Res. 82, 4039-4054.

Chapman, C. R., and A. L. Albee (Eds.) 1992. Mars Observer Special Issue. J. Geophys. Res. 97.

Chapman, M. G. 1994. Evidence, age, and thickness of a frozen paleolake in Utopia Planitia, Mars. Icarus 109, 393-406.

Christiansen, E. H. 1989. Lahars in the Elysium region of Mars. Geology 17, 203-206.

Christensen, P. R., D. L. Anderson, S. C. Chase, R. N. Clark, H. H. Kieffer, M. C. Malin, J. C. Pearl, J. Carpenter, N. Bandiera, F. G. Brown, and S. Silverman 1992. Thermal emission spectrometer experiment: Mars Observer Mission. J. Geophys. Res. 97, 7719-7734.

Christner, B. C., E. Mosley-Thompson, L. G. Thompson, V. Zagorodnov, K. Sandman, and J. N. Reeve 2000. Recovery and identification of viable bacteria immured in glacial ice. Icarus 144, 479-485.

Clark, B. C. 1998. Surviving the limits to life at the surface of Mars. J. Geophys. Res. 103, 28,545-28,556.

Clifford, S. M. 1987. Polar basal melting on Mars. J. Geophys. Res. 92, 91359152.

Clifford, S. M. 1993. A model for the hydrologic and climatic behavior of water on Mars. J. Geophys. Res. 98, 10,973-11,016.

Clifford, S. M., and D. Hillel 1983. The stability of ground ice in the equatorial region of Mars. J. Geophys. Res. 88, 2456-2474.

Clifford, S. M., and T. J. Parker 1999. Hydraulic and thermal arguments regarding the existence and fate of a primordial martian ocean. Lunar Planet. Sci. Conf. 30th, Abstract 1619. [CD-ROM]

Clifford, S. M., D. A. Fisher, and J. W. Rice, Jr. 2000. Introduction to the Mars Polar Science Special Issue; Exploration platforms, technologies, and potential future missions. Icarus 144, 205-209.

Costard, F. M., and J. S. Kargel 1995. Outwash plains and thermokarst on Mars. Icarus 114, 93-112.

Cowan, D. A. 1999. Life in extreme thermal environments: Implications for exobiology. In The Search for Life on Mars (J. Hiscox, Ed.), pp. 37-48. British Interplanetary Society, London.

Cutts, J. A. 1973. Nature and origin of layered deposits on the martian polar regions. J. Geophys. Res. 78, 4231-4249.

Cutts, J. A., and B. H. Lewis 1982. Models of climate cycles recorded in martian polar layered deposits. Icarus 50, 216-244.

Cutts, J. A., K. R. Blasius, G. A. Briggs, M. H. Carr, R. Greeley, and H. Masursky 1976. North polar region of Mars: Imaging results from Viking 2. Science 194, 1329-1337.

Cutts, J. A., K. R. Blasius, and W. J. Roberts 1979. Evolution of martian polar landscapes: Interplay of long-term variations in perennial ice cover and dust storm intensity. J. Geophys. Res. 84, 2975-2993.

Cutts, J. A., J. B. Pollack, A. D. Howard, and O. B. Toon 1981. Quasi-periodic climatic changes on Mars and Earth. Eos. Trans. Am. Geophys. Union 62, 755-759.

Dicken, A. P. 1995. Radiogenic Isotope Geology. Cambridge Univ. Press, Cambridge, UK. 
Doran, P. T., R. A. Wharton, D. J. Des Marais, and C. P. McKay 1998. Antarctic palaeolake sediments and the search for extinct life on Mars. J. Geophys. Res. 103, 28,481-28,493.

Durham, W. B., S. H. Kirby, and L. A. Stern 1997a. Creep of water ices at planetary conditions: A compilation. J. Geophys. Res. 102, 16,29316,302 .

Durham, W. B., S. H. Kirby, and L. A. Stern 1997b. Correction to "Creep of water ices at planetary conditions: A compilation." J. Geophys. Res. 102, 28,725.

Durham, W. B., S. H. Kirby, and L. A. Stern 1999. The rheology of solid carbon dioxide: New measurements. Lunar Planet. Sci. Conf. 30th, Abstract 2017. [CD-ROM]

Dzurisin, D., and K. R. Blasius 1975. Topography of the polar layered deposits of Mars. J. Geophys. Res. 80, 3286-3306.

Ehling-Schulz, M., W. Bilger, and S. Scherer 1997. UV-B-induced synthesis of photoprotective pigments and extracellular polysaccharides in the terrestrial cyanobacterium Nostoc commune. J. Bacteriol. 179, 1940-1945.

Fanale, F. P. 1976. Martian volatiles: Their degassing history and geochemical fate. Icarus 28, 179-202.

Fanale, F. P., J. R. Salvail, W. B. Banerdt, and R. S. Saunders 1982. Mars: The regolith-atmosphere-cap system and climate change. Icaurs 50, 381-407.

Fanale, F. P., J. R. Salvail, A. P. Zent, and S. E. Postawko 1986. Global distribution and migration of subsurface ice on Mars. Icarus 67, 1-18.

Farmer, C. B., and P. E. Doms 1979. Global and seasonal variations of water vapor on Mars and the implications for permafrost. J. Geophys. Res. 84, 2881-2888.

Farmer, C. B., D. W. Davies, and D. D. LaPorte 1976. Mars: Northern summer ice cap-Water vapor observations from Viking 2. Science 194, 13391340.

Farmer, J. D. 1996. Hydrothermal processes on Mars: An assessment of present evidence. In Evolution of Hydrothermal Systems on Earth (and Mars?) (G. Bock and J. Goode, Eds.), pp. 273-299. Wiley, New York.

Farmer, J.D. 1999. Implementing a strategy to explore for ancient martian life. In The Search for Life on Mars (J. Hiscox, Ed.), pp. 58-62. British Interplanetary Society, London.

Farmer, J. D., and D. J. Des Marais 1999. Exploring for a record of ancient martian life. J. Geophys. Res. 104, 26,977-26,995.

Fishbaugh, K., and J. W. Head III 1999a. North polar region of Mars: Topography of cirumpolar deposits from MOLA data. Lunar Planet. Sci. Conf. 30th, Abstract 1401. [CD-ROM]

Fishbaugh, K., and J. W. Head III 1999b. The geometry of Chasma Boreale, Mars using Mars Orbiter Laser Altimeter (MOLA) data: A test of the catastrophic outflow hypothesis of formation. In The Fifth-International Conference on Mars. Lunar and Planetary Institute, No. 6817. [CD-ROM].

Fisher, D. A. 1993. If martian ice caps flow: Ablation mechanisms and appearance. Icarus 105, 501-511.

Fisher, D. A. 2000. Internal layers in an "accublation" ice cap: A test for flow. Icarus 144, 289-294.

Forget, F., and J. B. Pollack 1996. Thermal infrared observations of the condensing martian polar caps: $\mathrm{CO}_{2}$ ice temperatures and radiative budget. J. Geophys. Res. 101, 16,865-16,879.

Friedmann, E. I., and R. Ocampo-Friedmann 1995. A primitive cyanobacterium as pioneer microorganism for terraforming Mars. Adv. Space Res. 15, 243246.

Garvin, J. B., S. E. H. Sakimoto, J. J. Frawley, and C. Schnetzler 2000. North polar region craterforms on Mars: Geometric characteristics from the Mars Orbiter Laser Altimeter. Icarus 144, 329-352.

Gilichinsky, D. A. 1994. Viable Microorganisms in Permafrost. Russian Acad. Sci., Pushchino Instit. Soil Sci. Photosyn., Pushchino.

Gilichinsky, D. A. 1995. Permafrost microbiology. Permafrost Periglacial Processes 6, 281-291.
Gilichinsky, D. A., V. S. Soina, and M. A. Petrova 1993. Cryoprotective properties of water in the Earth cryolithosphere and its role in exobiology. Origins Life Evol. Biosphere 23, 65-75.

Gold, T. 1992. The deep, hot biosphere. Proc. Nati. Acad. Sci. 89, 6045-6049.

Grant, W. D., R. T. Gemmell, and T. J. McGenity 1998. Halobacteria: The evidence for longevity. Extremophiles 2, 279-287.

Greve, R. 2000. Waxing and waning of the perennial north polar $\mathrm{H}_{2} \mathrm{O}$ ice cap of Mars over obliquity cycles. Icarus 144, 419-431.

Guinness, E. A., C. E. Leff, and R. E. Arvidson 1982. Two Mars years of changes seen at the Viking landing sites. J. Geophys. Res. 87, 10,051-10,058.

Haberle, R. M., J. B. Pollack, J. R. Barnes, R. W. Zurek, C. B. Leovy, J. R. Murphy, J. Schaeffer, and H. Lee 1993. Mars atmospheric dynamics as simulated by the NASA/Ames general circulation model I. The zonal mean circulation. J. Geophys. Res. 98, 3093-3123.

Hansen, G. B. 1999. Control of the radiative behavior of the martian polar caps by surface $\mathrm{CO}_{2}$ ice: Evidence from the Mars Global Surveyor measurements. J. Geophys. Res. 104, 16,471-16,486.

Head, J. W., III, M. Kreslavsky, H. Hiesinger, M. Ivanov, S. Pratt, N. Seibert, D. E. Smith, and M. T. Zuber 1998. Oceans in the past history of Mars: Tests for their presence using Mars Orbiter Laser Altimeter (MOLA) data. Geophys. Res. Lett. 25, 4401-4404.

Herkenhoff, K. E. 2000. Geologic Map of the MTM-85000 Quadrangle, Planum Australe Region of Mars. U.S. Geological Survey Misc. Inv. Series Map $\mathrm{I}-2686$, in press.

Herkenhoff, K. E., and B. C. Murray 1990. High-resolution topography and albedo of the south polar layered deposits on Mars. J. Geophys. Res. 95, 14,511-14,529.

Herkenhoff, K. E., and J. J. Plaut 2000. Surface ages and resurfacing rates of the polar layered deposits on Mars. Icarus 144, 243-253.

Herkenhoff, K. E., and A. R. Vasavada 1999. Dark material in the polar layered deposits and dunes on Mars. J. Geophys. Res. 104, 16,487-16,500.

Herkenhoff, K. E., J. J. Plaut, and S. A. Nowicki 1997. Surface age and resurfacing rate of the north polar layered terrain on Mars. Lunar Planet. Sci. 28, 551.

Hodges, C. A., and H. J. Moore 1979. The subglacial birth of Olympus Mons and its aureoles. J. Geophys. Res. 84, 8061-8074.

Horowitz, N. H. 1979. Biological water requirements. In Strategies of Microbial Life in Extreme Environments (M. Shilo, Ed.), pp. 15-27. Verlag Chemie, New York.

Howard, A. D. 1978. Origin of the stepped topography of the martian poles. Icarus 84, 581-599.

Howard, A. D. 1981. Etched plains and braided ridges of the south polar region of Mars: Features produced by basal melting of ground ice? Repts. Planet. Geol. Prog. NASA TM 84211, 286-288.

Howard, A. D. 2000. The role of Eolian processes in forming surface features of the martian polar layered deposits. Icarus 144, 267-288.

Howard, A. D., J. A. Cutts, and K. R. Blasius 1982. Stratigraphic relationships within martian polar cap deposits. Icarus 50, 161-215.

Ingebritsen, S. E., and W. E. Sanford 1998. Groundwater in Geologic Processes. Cambidge Univ. Press, Cambridge, UK.

Ivanov, A. B., and D. O. Muhleman 2000. The role of sublimation for the formation of the northern ice cap: Results from the Mars Orbiter Laser Altimeter. Icarus 144, 436-448.

Jakosky, B. M., and C. B. Farmer 1982. The seasonal and global behavior of water vapor in the Mars atmosphere: Complete global results of the Viking atmospheric water detector experiment. J. Geophys. Res. 87, 29993019.

James, P. B., B. A. Cantor, M. C. Malin, K. Edgett, M. H. Carr, G. E. Danielson, A. P. Ingersoll, M. E. Davies, W. K. Hartmann, A. S. McEwen, L. A. Soderblom, P. C. Thomas, and J. Veverka 2000. The 1997 Spring Regression 
of the martian south polar cap: Mars Orbital Camera observations. Icarus 144, 410-418.

Johnson, C. L., S. C. Solomon, J. W. Head III, R. J. Phillips, D. E. Smith, and M. T. Zuber 2000. Lithospheric loading by the northern polar cap of Mars. Icarus 144, 313-328.

Jones, K. L., R. E. Arvidson, E. A. Guiness, S. L. Bragg, S. D. Wall, C. E. Carlston, and D. G. Pidek 1979. One Mars year: Viking Lander imaging observations. Science 204, 799-806.

Kargel, J. 1998. Posssible composition and dynamics of martian polar caps and controls on ice cap behavior. In First International Conference on Mars Polar Science and Exploration, LPI Contribution No. 953, pp. 22-23. Lunar and Planetary Institute, Houston.

Kargel, J. S., and R. G. Strom 1992. Ancient glaciation on Mars. Geology 20, 3-7.

Kargel, J. S., V. R. Baker, J. E. Begét, J. F. Lockwood, T. L. Péwé, J. S. Shaw, and R. G. Strom 1995. Evidence of continental glaciation in the martian northern plains. J. Geophys. Res. 100, 5351-5368.

Kennedy, M. J., S. L. Reader, and L. M. Swierczynski 1994. Preservation records of micro-organisms: Evidence of the tenacity of life. Microbiology 140, 25132529.

Kerry, K. R., D. R. Grace, R. Williams, and H. R. Burton 1977. Studies on some saline lakes of the Vestfold Hills. In Adaptations within Antarctic Ecosystems: Proceedings of the 3rd SCAR Symposium on Antarctic Biology (G. A. Llano, Ed.), pp. 839-858. Gulf Publishing, Houston.

Kieffer, H. H. 1979. Mars south polar spring and summer temperatures: A residual $\mathrm{CO}_{2}$ frost. J. Geophys. Res. 84, 8263-8288.

Kieffer, H. H., and A. P. Zent 1992. Quasi-periodic climate change on Mars. In Mars (H. H. Kieffer, B. M. Jakosky, C. W. Snyder, and M. S. Matthews, Eds.), pp. 1180-1220. Univ. of Arizona Press, Tucson.

Kieffer, H. H., S. C. Chase, Jr., T. Z. Martin, E. D. Miner, and F. D. Palluconi 1976. Martian north pole summer temperatures: Dirty water ice. Science 194, 1341-1344.

Kieffer, H. H., T. N. Titus, K. F. Mullins, and P. R. Christiansen 2000. Mars south polar spring and summer behavior observed by TES; seasonal cap evolution controlled by grain size. J. Geophys. Res., in press.

Klein, H. P. 1992. The Viking biology experiments: Epilogue and prologue. Origins Life Evol. Biosphere 21, 255-261.

Klien, H. P., N. H. Horowitz, and K. Biemann 1992. The search for extant life on Mars. In Mars (H. H. Kieffer, B. M. Jakosky, C. W. Snyder, and M. S. Matthews, Eds.), pp. 1221-1233. Univ. of Arizona Press, Tucson.

Kossacki, K. J., W. J. Markiewicz, and H. U. Keller 2000. Small scale trench in the martian soil: Conditions for condensation of atmospheric volatiles. Icarus 144, 463-478.

Kuhn, W. R., and S. K. Atreya 1979. Solar radiation incident on the martian surface. J. Molec. Evol. 14, 57-64.

Kuzmin, R. O. 1983. Cryolithosphere of Mars. Izd-vo "Nauka" [Izdatel'stvo Nauka], Moscow.

Larsen, J., and D. Dahl-Jensen 2000. Interior temperatures of the northern polar cap on Mars. Icarus 144, 456-462.

Laskar, J., and P. Robutel 1993. The chaotic obliquity of the planets. Nature 361, 608-612.

Leighton, R. B., and B. C. Murray 1966. Behavior of carbon dioxide and other volatiles on Mars. Science 153, 136-144.

Lepper, K., and S. W. S McKeever 1998. Luminescence dating: A tool for martian eolian geochronology. In First International Conference on Polar Science and Exploration, LPI Contribution 953, pp. 24-25. Lunar and Planetary Institute, Houston.

Lepper, K., and S. W. S. McKeever 2000. Characterization of fundamental luminescence properties of the Mars soil simulant JSC Mars-1 and their relevance to absolute dating of martian Eolian sediments. Icarus 144, 295-301.
Lorenz, R. D. 2000. Microtektites on Mars: Volume and texture of distal impact ejecta deposits. Icarus 144, 353-366.

Lucchitta, B. K. 1981. Mars and Earth: Comparison of cold-climate features. Icarus 45, 264-303.

Lucchitta, B. K. 1982. Ice sculpture in the martian outflow channels. J. Geophys. Res. 87, 9951-9973.

Lucchitta, B. K., H. M. Ferguson, and C. A. Summers 1986. Sedimentary deposits in the northern lowland plains, Mars. J. Geophys. Res. Suppl. Proc. Lunar Planet. Sci. Conf. 17th, 91, E166-E174.

Malin, M. C. 1986. Density of martian north polar layered deposits: Implications for composition. Geophys. Res. Lett. 13, 444-447.

Malin, M. C. 1998. Early MGS MOC results. Presentation at the First International Conference on Mars Polar Science and Exploration.

Malin, M. C., J. F. Bell III, W. M. Calvin, M. A. Caplinger, R. T. Clancy, R. M. Haberle, P. B. James, S. W. Lee, M. A. Ravine, P. Thomas, and M. J. Wolff 1999. The Mars Color Imager (MARCI) investigation on the Mars Climate Orbiter mission. Lunar Planet. Sci. Conf. 30th, Abstract 1437. [CD-ROM]

Malin, M. C., G. E. Danielson, A. P. Ingersoll, H. Masursky, J. Veverka, M. A. Ravine, and T. A. Soulanille 1992. Mars Observer Camera. J. Geophys. Res. 97, 7699-7718.

Marion, G. M. 1997. A theoretical evaluation of mineral stability in Don Juan Pond, Wright Valley, Victoria Land. Antarctic Sci. 9, 92-99.

Marshall, J. M., Anderson, M. Buehler, M. Frant, S. Fuerstenau, M. Hecht, U. Keller, W. Markiewicz, T. Meloy, T. Pike, W. Schubert, and P. Smith 1999. The MECA payload as a dust analysis laboratory on the MSP 2001 Lander. Lunar Planet. Sci. Conf. 30th, Abstract 1163.

Masursky, H., J. M. Boyce, A. L. Dial, G. G. Schaber, and M. E. Strobell 1977. Classification and time of formation of martian channels based on Viking data. J. Geophys. Res. 82, 4016-4038.

McCleese, D. J., R. D. Haskins, J. T. Schofield, R. W. Zurek, C. B. Leovy, D. A. Paige, and F. W. Taylor 1992. Atmosphere and climate studies of Mars using the Mars Observer Pressure Modulator Infrared Radiometer. J. Geophys. Res. 97, 7735-7757.

McKay, D. S., E. K. Gibson, Jr., K. L. Thomas-Keprta, H. Vali, C. S. Romanek, S. J. Clemett, X. D. F. Chillier, C. R. Maechling, and R. N. Zare 1996. Search for past life on Mars: Possible relic biogenic activity in martian meteroite ALH84001. Science 273, 924-930.

McKay, C. P., R. L. Mancinelli, C. R. Stoker, and R. A. Wharton, Jr. 1992. The possibility of life on Mars during a water-rich past. In Mars (H. H. Kieffer, B. M. Jakosky, C. W. Snyder, and M. S. Matthews, Eds.), pp. 1234-1245. Univ. of Arizona Press, Tucson.

McSween, H. Y., and R. P. Harvey 1998. Brine evaporation: An alternative model for the formation of carbonates in Allan Hills 84001. Meteorit. Planet. Sci. 32, p. A103.

Mellon, M. T. 1996. Limits on the $\mathrm{CO}_{2}$ content of the martian polar deposits. Icarus 124, 268-279.

Mellon, M. T., and B. M. Jakosky 1993. Geographic variations in the thermal and diffusive stability of ground ice on Mars. J. Geophys. Res. 98, 3345-3364.

Metzger, S. M. 1992. The eskers of New York state: Formation process implications and esker-like features on the planet Mars. Proc. Lunar Planet. Sci. Conf. 23rd, 901-902. [Abstract]

Mouginis-Mark, P. J. 1985. Volcano-ground ice interactions in Elysium Planitia. Icarus 64, 265-284.

Muhleman, D. O., A. W. Grossman, and B. J. Butler 1995. Radar investigation of Mars, Mercury, and Titan. Ann. Rev. Earth Planet. Sci. 23, 337374.

Murray, B. C., L. A. Soderblom, J. A. Cutts, R. P. Sharp, D. J. Milton, and R. B. Leighton 1972. Geological framework of the south polar region of Mars. Icarus 17, 328-345.

Murray, B. C., W. R. Ward, and S. C. Yeung 1973. Periodic insolation variations on Mars. Science 180, 638-640. 
Nealson, K. H. 1997. The limits of life on Earth and searching for life on Mars. J. Geophys. Res. 102, 23,675-23,686.

Neugebauer, G., G. Munch, H. Kieffer, S. C. Chase, Jr., and E. Miner 1971. Mariner 1969 infrared radiometer results: Temperatures and thermal properties of the martian surface. Astron. J. 76, 719-728.

Nye, J. F. 1959. The motion of ice sheets and glaciers. J. Glaciol 3, 493-507.

Nye, J. F. 1976. Water flow in glaciers: Jökulhlaups, tunnels and veins. J. Glaciol. 17, 181-207.

Nye, J. F., W. B. Durham, P. M. Schenk, and J. M. Moore 2000. The instability of a south polar cap on Mars composed of carbon dioxide. Icarus 144, 449-455.

Onstott, T. C., T. J. Phelps, F. S. Colwell, D. Ringelberg, D. C. White and D. R. Boone 1998. Observations pertaining to the origin and ecology of microorganisms recovered from the deep subsurface of Taylorsville Basin, Virginia. Geomicrobiol.J. 15, 353-385.

Oren, A., M. Kühl, and U. Karsten 1995. An endoevaporitic microbial mat within a gypsum crust: Zonation of phototrophs, photopigments, and light penetration. Marine Ecol. Progr. Ser. 128, 151-159.

Paige, D. A., and A. P. Ingersoll 1985. Annual heat balance of martian polar caps: Viking observations. Science 228, 1160-1168.

Paige, D. A., and K. D. Keegan 1994. Thermal and albedo mapping of the polar regions of Mars using Viking thermal mapper observations: 2. South polar region. J. Geophys. Res. 99, 25,993-26,031.

Paige, D. A., and H. H. Kieffer 1986. Non-linear frost albedo feedback on Mars: Observations and models. In Workshop on the Evolution of the Martian Atmosphere, LPI Tech Rept. 86-07, pp. 33-34. Lunar and Planetary Institute, Houston.

Paige, D. A., J. E. Bachman, and K. D. Keegan 1994. Thermal and albedo mapping of the polar regions of Mars using Viking thermal mapper observations: 1. North polar region. J. Geophys. Res. 99, 25,959-25,991.

Parker, T. J., D. S. Gorsline, R. S. Saunders, D. C. Pieri and D. M Schneeberger 1993. Coastal geomorphology of the martian northern plains, J. Geophys. Res. 98, 11,061-11,078.

Parker, T. J., R. S. Saunders, and D. M. Schneeberger 1989. Transitional morphology in West Deutronilus Mensae, Mars: Implications for modification of the lowland/upland boundary. Icarus 82, 111-145.

Paterson, W. S. B. 1981. The Physics of Glaciers. Pergamon, New York.

Pathare, A. V., and D. A., Paige 1998. Recent liquid water in the polar regions of Mars. In First International Conference on Mars Polar Science and Exploration, LPI Contribution 953, p. 31. Lunar and Planetary Institute, Houston.

Plaut, J. J. 1999. Probing the crust of Mars with orbital sounding radar: The MARSIS Experiment on Mars Express. Lunar Planet. Sci. Conf. 30th, Abstract 1136. [CD-ROM]

Plaut, J. J., R. Kahn, E. A. Guinness, and R. E. Arvidson 1988. Accumulation of sedimentary debris in the south polar region of Mars and implications for climate history. Icarus 76, 357-377.

Pollack, J. B., D. Colburn, F. M. Flasar, R. Kahn, C. Carlston, and D. Pidek 1979. Properties and effects of dust particles suspended in the martian atmosphere. J. Geophys. Res. 84, 2929-2945.

Pollack, J. B., J. F. Kasting, S. M. Richardson, and K. Poliakoff 1987. The case for a wet, warm climate on early Mars. Icarus 71, 203-224.

Priscu, J. C., C. H. Fritsen, E. E. Adams, S. J., Giovanni, H. W. Paerl, C. P. McKay, P. T. Doran, D. A. Gordon, B. D. Lanoil, and J. L. Pinckney 1998. Perennial Antarctic lake ice: An oasis for life in a polar desert. Science 280, 2095-2098.

Rice, J. W., Jr. 1994. Analogs and interpretations for the martian thumbprint terrain and sinuous ridges. Proc. Lunar Planet. Sci. Conf. 25th, 1127-1128.

Ross, R. G., and J. S. Kargel, 1998, Thermal conductivity of Solar System ices, with special reference to martian polar caps. In Solar System Ices (B. Schmitt, C. de Bergh, and M. Festou, Eds.), pp. 32-36. Kluwer Academic, Dordrecht.

Rossbacher, L. A., and S. Judson 1981. Ground ice on Mars: Inventory, distribution, and resulting landforms. Icarus 45, 39-59.
Ruff, S. W. 1994. Comparison of Mars sinuous ridges with terrestrial linear dunes: Observations from the field. Proc. Lunar Planet. Sci. Conf. 25th, 11711172.

Schenk, P. M., and J. M. Moore 2000. Stereo topography of the south polar region of Mars: Volatile inventory and Mars polar lander landing site. J. Geophys. Res., in press.

Schopf, J. W. 1993. Microfossils of the early Archean Apex chert: New evidence of the antiquity of life. Science 260, 640-646.

Schubert, G., S. C. Solomon, D. L. Turcotte, M. J. Drake, and N. H. Sleep 1992. Origin and thermal evolution of Mars. In Mars (H. H. Kieffer, B. M. Jakosky, C. W. Snyder, and M. S. Matthews, Eds.), pp. 147-183. Univ. of Arizona Press, Tucson.

Scott, D. H., M. G. Chapman, J. W. Rice, Jr., and J. M. Dohm 1992. New evidence of lacustrine basins on Mars: Amazonis and Utopia Planitiae. Proc. Lunar Planet. Sci. Conf. 22nd, 53-62.

Scott, D. H., J. M. Dohm, and J. W. Rice, Jr. 1995. Map showing channels and possible paleolake basins. U.S. Geol. Surv. Misc. Inv. Series Map I-2461.

Scott, D. H., J. W. Rice, Jr., and J. M. Dohm 1991. Martian lacustrine basins and reassessment of fluvial history: Exobiologic implications. Origin Life Evol. Biosphere 21, 189-198.

Smith, D. E., and M. T. Zuber 1998. An overview of observations of Mars north polar region from the Mars Global Surveyor Laser Altimeter. In First International Conference on Polar Science and Exploration, LPI Contribution 953, pp. 35-36. Lunar and Planetary Institute, Houston.

Smith, D. E., M. T. Zuber, S. C. Solomon, R. J. Phillips, J. W. Head, J. B. Garvin, W. B. Banerdt, H. V. Frey, D. O. Muhleman, G. H. Pettengill, G. A. Neumann, F. G. Lemoine, J. B. Abshire, O. Aharonson, C. D. Brown, S. A. Hauck, A. B. Ivanov, P. J. McGovern, H. J. Zwally, and T. C. Duxbury 1999. The global topography of Mars and implications for surface evolution. Science 284, 1495-1503.

Smith, P. H., M. G. Tomasko, D. Britt, D. G. Crowe, R. Reid, H. U. Keller, N. Thomas, F. Glien, P. Rueffer, R. Sullivan, R. Greeley, J. M. Knudsen, M. B. Madsen, H. P. Gunnlaugsson, S. F. Hviid, W. Goetz, L. A. Soderblom, L. Gaddis, and R. Kirk 1997. The imager for Mars Pathfinder experiment. J. Geophys. Res. 102, 4003-4025.

Smrekar, S., D. Catling, R. Lorenz, J. Magalhães, J. Moersch, P. Morgan, J. Murphy, B. Murray, M. Presley-Holloway, A. Yen, A. Zent, and D. Blaney 1999. Deep Space 2: The Mars Microprobe Mission. J. Geophys. Res. 104, 27,013-27,030.

Soderblom, L. A., M. C. Malin, J. A. Cutts, and B. C. Murray 1973. Mariner 9 observations of the surface of Mars in the north polar region. J. Geophys. Res. 78, 4197-4210.

Squyres, S. W. 1979. The evolution of dust deposits in the martian north polar region. Icarus 40, 244-261.

Squyres, S. W., and M. H. Carr 1986. Geomorphic evidence for the distribution of ground ice on Mars. Science 231, 249-252.

Squyres, S. W., R. Arvidson, J. F. Bell III, M. Carr, P. Christensen, D. Des Marais, C. d'Uston, T. Economou, S. Gorevan,G. Klingelhöfer, L. Haskin, K. Herkenhoff, A. Knoll. J. M. Knudsen, A. L. Lane, V. Linkin, M. Malin, H. McSween, R. Morris, R. Rieder, M. Sims, L. Soderblom, H. Wänke, and T. Wdowiak 1999. The Mars 2001 Athena Precursor Experiment (APEX). In Workshop on Mars 2001: Integrated Science in Preparation for Sample Return and Human Exploration, pp. 86-88. Lunar and Planetary Institute, Houston.

Squyres, S. W., D. E. Wilhelms, and A. C. Moosman 1987. Large-scale volcanoground ice interactions on Mars. Icarus 70, 385-408.

Stevens, T. O., and J. P. McKinley 1996. Lithoautotrophic microbial ecosystems in deep basalt aquifers. Science 270, 450-454.

Tanaka, K. L. 2000. Dust and ice deposition in the martian geologic record. Icarus 144, 254-266. 
Tanaka, K. L., and D. H. Scott, 1987. Geologic map of the polar regions of Mars. U.S. Geological Survey Misc. Inv. Map I-1802-C, scale 1:15,000,000.

Thomas, P. 1982. Present wind activity on Mars: Relation to large latitudinally zoned sediment deposits, J. Geophys. Res. 87, 9999-10,008.

Thomas, P. C., and C. Weitz 1989. Dune sand materials and polar layered deposits on Mars. Icarus 81, 185-215.

Thomas, P., S. Squyres, K. Herkenhoff, B. Murray, and A. Howard 1992. Polar deposits on Mars. In Mars (H. H. Kieffer, B. M. Jakasky, C. W. Snyder, and M. S. Mathews, Eds.), pp. 767-795. Univ. of Arizona Press, Tucson.

Toon, O. B., J. B. Pollack, W. Ward, J. A. Burns, and K. Bilski 1980. The astronomical theory of climatic change on Mars. Icarus 44, 552-607.

Touma, J., and J. Wisdom 1993. The chaotic obliquity of Mars. Science 259, 1294-1297.

Treiman, A. H. 1999. The status of martian life in meteorite ALH84001. EOS Trans. Am. Geophys. Union 80, 205.

Tricart, J. L. F. 1988. Environmental change of planet Mars demsonstrated by landforms. Z. Geomorph. 32, 385-407.

Tyler, G. L., G. Balmino, D. P. Hinson, W. L. Sjogren, D. E. Smith, R. Woo, S. W. Asmar, M. J. Connally, C. L. Hamilton, and R. A. Simpson 1992. Radio science investigations with Mars Observer. J. Geophys. Res. 97, 7759-7779.

Vasavada, A. R., J. P. Williams, D. A. Paige, K. E. Herkenhoff, N. T. Bridges, R. Greeley, B. C. Murray, D. S. Bass, and K. S. McBride 2000. Surface properties of Mars' polar layered deposits and polar landing sites. J. Geophys. Res., in press.

Vorobyova, E., V. Soina, M. Gorlenko, N. Minkovskaya, N. Zalinova, A. Mamukelashvili, D. Gilichinsky, E. Rivkina, and T. Vishnivatskaya 1997. The deep cold biosphere: Facts and hypothesis. FEMS Microbiol. Rev. 20, 277-290.

Wall, S. D 1981. Analysis of condensates formed at the Viking 2 Lander site: The first winter. Icarus 47, 173-183.

Wallace, D., and C. Sagan 1979. Evaporation of ice in planetary atmospheres: Ice-covered rivers on Mars. Icarus 39, 385-400.

Ward, W. R. 1979. Present obliquity oscillations of Mars: Fourth-order accuracy in orbital e and I. J. Geophys. Res. 84, 237-241.

Ward, W. R. 1992. Long-term orbital and spin dynamics of Mars. In Mars (H. H. Kieffer, B. M. Jakosky, C. W. Snyder, and M. S. Matthews, Eds.), pp. 298-320. Univ. of Arizona Press, Tuscon.
Warren, P. H. 1998. Petrologic evidence for low-temperature, possible floodevaporitic origin of carbonates in the Allan Hills 84001 meteorite. Meteorit Planet. Sci. 32, A162.

Weiss, B. P., and A. P. Ingersoll 2000. Cold spots in the martian polar regions: Evidence of carbon dioxide depletion? Icarus, 144, 432-435.

Wynn-Williams, D. D. 1999. Antarctica as a model for ancient Mars. In The Search for Life on Mars (J. A. Hiscox, Ed.), pp. 49-57. British Interplanetary Society, London.

Wynn-Williams, D. D. 2000. Cyanobacteria in deserts-Life at the limit? In The Ecology of Cyanobacteria: Their Diversity in Time and Space (B. A. Whitton and M. Potts, Eds.), pp. 341-366. Kluwer Academic, Dordrecht.

Zent, A. P., and F. P. Fanale 1986. Possible Mars brines: Equilibrium and kinetic considerations. J. Geophys. Res. 91, Proc. Lunar Planet. Sci. Conf. 16th, D439-D445.

Zent, A. P., F. P. Fanale, J. R. Salvail, and S. E. Postawko 1986. Distribution and state of $\mathrm{H}_{2} \mathrm{O}$ in the high-latitude shallow subsurface of Mars. Icarus 67 , 19-36.

Zuber, M. T., L. Lim, and J. Zwally 1999. The role of viscous deformation in the morphology of the martian north polar cap. In First International Conference on Mars Polar Science and Exploration, LPI Contribution No. 953, pp. 45-46. Lunar and Planetary Institute, Houston.

Zuber, M. T., D. E. Smith, S. C. Solomon, D. O. Muhleman, J. W. Head, J. B. Garvin, J. B. Abshire, and J. L. Bufton 1992. The Mars Observer Laser Altimeter investigation. J. Geophys. Res. 97, 7781-7798.

Zuber, M. T., D. E. Smith, S. C. Solomon, J. B. Abshire, R. S. Afzal, O. Aharonson, K. Fishbaugh, P. G. Ford, H. V. Frey, J. B. Garvin, J. W. Head, A. B. Ivanov, C. L. Johnson, D. O. Muhleman, G. A. Neumann, G. H. Pettengill, R. J. Phillips, X. Sun, H. J. Zwally, W. B. Banerdt, and T. C. Duxbury 1998. Observations of the north polar region of Mars from the Mars Orbiter Laser Altimeter. Science 282, 2053-2060.

Zvyagintsev, D. G., D. A. Gilichinskii, S. A. Blagodatskii, E. A. Vorob'eva, G. M. Khlebnikova, A. A. Arkhangelov, and N. N. Kudryavtseva 1985. Survival time of microorganisms in permanently frozen sedimentary rocks and buried soils. Mikrobiologiya 54, 155-161.

Zvyagintsev, D. G., D. A. Gilichinskii, G. M. Khlebnikova, D. G. FedorovDavydov, and N. N. Kudryavtseva 1990. Comparative characteristics of microbial cenoses from permafrost rocks of different age and genesis. Mikrobiologiya 59, 491-498. 